\title{
Ariadna danza: lecturas feministas de Michel Foucault
}

\section{Ariadne dance: feminist readings of Michel Foucault}

\author{
Patricia Amigot Leache y Margot Pujal i Llombart \\ Universidad Pública de Navarra y Universitat Autònoma de Barcelona \\ Patricia.amigot@unavarra.es Margot.pujal@uab.es
}

\begin{abstract}
Resumen
La obra de Michel Foucault ha sido objeto de diversas e intensas lecturas feministas. La valoración de la pertinencia de los análisis y de las elaboraciones conceptuales foucaultianas alcanza en tales lecturas una cierta disparidad. Por ello consideramos que el diálogo establecido ha sido y es complejo pero de gran interés, tanto para la práctica feminista como para cualquier analítica del poder. En este artículo par intentamos reflexionar, sin ánimo de sintetizar exhaustivamente, acerca de los elementos de confluencia y discrepancia que las autoras feministas han sostenido con la obra de Michel Foucault. Por último, subrayamos cómo una lectura de la obra de Foucault que incorpore elementos de la crítica feminista puede permitir una profundización en el análisis de las relaciones de poder.
\end{abstract}

Palabras clave: Feminismo; Poder; Sujeto; Género

\section{Abstract}

The work of Michel Foucault has been read from a eminist point of view in different ways. Feminist readers of Foucault have different opinions on the relevance and usefulness of Foucault's concepts and analyses. We argue that the dialogue between both positions has been complex but extremely interesting, both for feminist practices and for any analytics of power. In this paper we discuss some of the basic elements of agreement and disagreement that feminist authors have showed with Foucault. We finally argue that reading Foucault's work taking into account its feminist critique may be very useful in developing a deeper analysis of power relations.

Keywords: Feminism; Power; Subject; Gender

\section{Introducción: El hilo de Ariadna}

Para celebrar la publicación en 1969 del libro de Gilles Deleuze Diferencia y repetición, Michel Foucault inventó una fábula. El texto, que sería publicado bajo el título Ariadna se ha colgado, es una hermosa e intensa introducción al hacer filosófico que Deleuze ponía en juego, la filosofía de la diferencia, frente a la ya muerta "filosofía de la representación" (Foucault, 1969a: 797). Foucault ensalza con pasión ese "teatro del ahora", esa obra que pulveriza lo único, lo claro y lo acumulativo para estallar en murmullos oscuros, en gestos que rompen con orígenes e identidades y permiten pensar, por fin, las repeticiones y las diferencias. Éstas, obstinadamente enmascaradas bajo la semejanza o la evidencia en la voz "monárquica" de los filósofos occidentales, se multiplican en el pensamiento intempestivo de Deleuze y en las palabras apasionadas que Foucault le dedica.

La fábula refigura la trama del mito de Teseo y el minotauro, modificando la urdimbre de sus hilos. Seccionando, mejor dicho, las secuencias conocidas y previsibles. Algo nuevo irrumpe -como es, de 
hecho, el libro de Deleuze- y el relato, se repite en un movimiento nuevo y paradójico. Empujamos la puerta y se ilumina la escena. Ariadna,

"cansada de esperar que Teseo regresara del laberinto, de acechar su paso igual y de reconocer su rostro tras todas las sombras que pasan, Ariadna acaba de colgarse. Del hilo amorosamente tejido de la identidad, de la memoria y del reconocimiento, su cuerpo pensativo gira sobre sí mismo. Sin embargo, Teseo, rotas las amarras, no regresa. [...] él avanza, cojea, danza, salta" (Foucault, 1969a: 795).

Los protagonistas, repetidos y diferentes, adquieren tonalidades intensas: ella, la de la muerte; él, la de la vida dionisíaca. Un poco más adelante, Foucault caracteriza el pensamiento mismo como "gesto, salto, danza". Teseo es, hace, pensamiento. Ariadna se ha colgado. Su acción -luego relatada en términos pasivos: "Ariadna ha sido abandonada"- es, literalmente, el sacrificio que libera el pensamiento de sus amarras identitarias y le permite actuar intensamente. Opone a la firmeza del hilo filosófico occidental la violencia última -"toda la historia del pensamiento occidental está por reescribir"- y desencadena la posibilidad de multiplicar, con estrépito y furor, "esas diferencias que somos, esas diferencias que hacemos, esas diferencias entre las cuales erramos" (Foucault, 1969a: 799).

La trama se teje con hilos de fuego. En escena, los personajes son, simultáneamente, su propia transfiguración. Solo Ariadna se muestra idéntica, pues nada cambia en la muerte. Una muerte, curiosamente, repetida mientras otros cuerpos se desplazan, vibran y se inventan en la oscuridad o en el fulgurante destello de un relámpago:

"En el escenario desnudo de cada página Ariadna es estrangulada, Teseo baila, el Minotauro ruge y el cortejo del dios múltiple estalla de risa". (Foucault, 1969a: 796).

Es extraño que Ariadna sea sacrificada en esta fábula para que un gesto de liberación se produzca ${ }^{1}$. Ese hilo seguro, certera guía de un pensamiento decoroso y asfixia de la diferencia, debía romperse y liberar, de-sujetar, a Teseo. Es como si Ariadna asumiera en sí toda la determinación del pensamiento occidental -la identidad, la memoria, el reconocimiento- y la pagara con su pasividad/muerte. Su cuerpo "pensativo" oscila inerte liberando de su atadura a aquel que se hallaba al otro extremo del hilo. Dejando oscilante, a su vez, el subtexto de género que palpita en la fábula, podríamos proponer otra. Esa "alta realeza del Sujeto" construida en la filosofía occidental moderna implicaba una relación invisible con una/s alteridad/es construida/s: en la trama de los discursos un firme hilo enlazaba el sujeto trascendente y racional, unitario y coherente con otros a su sombra como "todo el sexo bello" en expresión kantiana-, y que operaban como excepción a, -pero permitiéndola - tan excelsa altura, a costa de imantar sobre sí lo sensible, corporal, emocional e irracional que ha caracterizado la configuración de lo femenino. Lo femenino, como Ariadna, particular pero sobredeterminada, contrapunto deficitario o excepcional de esos universales.

\footnotetext{
${ }^{1}$ Recuerda la reflexión que Maite Larrauri recoge de Luce Irigaray acerca de la recurrente alusión de los filósofos a un segundo nacimiento: el mito de un origen otro, no el de la dependencia y el cuerpo de la madre (Larrauri, 1996, p. 19); en este caso se trata de una ruptura fundamental, no para ser uno mismo, sino para dejar de serlo.
} 
La fábula comienza y ninguna esencia ontológica nos impide imaginar otros cursos de acción y repeticiones que van difiriendo. Ariadna, sujeta a ese tejido identitario que la constituía de manera específica y cansada de una espera preceptiva, avanza. Se pierde para desplazarse por un laberinto sujeta sólo a su propio tránsito, haciendo también las diferencias que la constituyen, repitiéndose en movimientos que la vuelven distinta a sí misma. Multiplica las palabras para decirse y fractura a su paso las verdades que la representaban; cada vez más lejos de una imagen siempre igual a sí misma en todas las Ariadnas repetidas. Un tránsito para deshacer itinerarios previsibles. Ya no sirven los viejos hilos. Los nuevos se tejen en paradojas y contradicciones. En nuevas prácticas políticas y de pensamiento establecidas en escenarios que van transformándose.

Tanto la obra de Foucault como la heterogénea y prolija escena de la acción y el pensamiento feminista, entre otras, han quebrado los hilos de los relatos identitarios y los trayectos repetidos que éstos establecían. Han impugnado esencias y universales desde posiciones políticas asumidas y han multiplicado los conflictos y las posibilidades. Su diálogo, fluido o paradójico, puede seguir alentando nuevas prácticas y nuevos tránsitos.

\section{La pertinencia de un diálogo}

La obra de Michel Foucault ha sido relevante, entre otras, para la teorización feminista, entendida ésta como una práctica discursiva que asume específicamente su dimensión política. El feminismo, como han señalado muchas autoras, tiene un estatus político paradójico. Es, a la vez, crítica del pensamiento moderno y de los postulados de la llustración, pero también heredero de algunos de ellos que, en ocasiones, replantea con radicalidad. ${ }^{2}$ Esta ambivalencia genealógica en los desplazamientos del pensamiento y la práctica feminista, vinculada directamente a las situaciones estratégicas e históricas que pretende transformar, puede resultar un inquietante pero fértil terreno de reflexión y revisión continua de sus prácticas y sus discursos. Sin entrar en la consideración detenida de los debates intensísimos en torno a la Modernidad/Posmodernidad o la tensión entre las reivindicaciones de reconocimiento/redistribución vinculadas a lo que se ha denominado feminismo de la diferencia-feminismo de la igualdad (Benhabib, 1992; Amorós, 1994, 1997; Nicholson, 1990; Fraser \& Hanneth, 1998), nos gustaría simplemente indicar la preeminencia de su dimensión deliberativa y política, en tanto reflexión sobre los efectos de dominio que para las mujeres pueden derivarse de diferentes ámbitos epistemológicos. De ello deriva un proceso permanente de revisión, insidioso en ocasiones, pero claramente saludable puesto que evidencia con la práctica que no hay posiciones de resistencia intrínsecamente "adecuadas" y definitivas, o que trasciendan sus contextos de emergencia.

Judith Butler, conocida por su compleja impugnación de esencialismos genéricos y sexuales, considera que el marco de la diferencia sexual, desde una estrategia política, debería mantenerse porque:

"trae a debate la continua realidad cultural y política de la dominación patriarcal, porque nos recuerda que, sean cuales sean las permutaciones de género que se den, no desafían plenamente el marco dentro del cual se desarrollan, ya que este

\footnotetext{
${ }^{2}$ Como lo considera Celia Amorós, entre otras, analizando el vínculo entre Feminismo e llustración "el
} feminismo se convierte en la coherente radicalización del proyecto ilustrado" (Amorós, 1994: 343). 
marco persiste a un nivel simbólico sobre el que es más difícil intervenir". (Butler, 2001:12).

Una posición feminista, por lo tanto, se relaciona con la voluntad específica de subvertir un orden androcéntrico que configura unas determinadas identidades sexuales normativas y genera efectos de dominación sobre las mujeres. No obstante, ni las definiciones son prescriptivas ni necesarias, ni los feminismos constituyen una práctica homogénea y unificada. Antes bien, son el escenario en el que se establecen tensiones y desplazamientos continuos. Para parte de la práctica feminista los fundamentos de ésta son contingentes y los marcos normativos o reguladores, precarios, contrastados o valorados en función de criterios inmanentes. Lo cual permite un ejercicio político situado y parcial, abierto y de límites porosos.

Esta especificidad política, a su vez, actúa como dispositivo problematizador también de aquellas corrientes que, nacidas de un gesto instituyente en contra de lo académicamente instituido, pueden derivar en sedimentaciones más o menos oficiales y reconocidas que sean ciegas a efectos de poder nuevos. Dentro de los diferentes "postestructuralismos" la lectura feminista puede suponer un "grano de arena", parafraseando a Rosi Braidotti (2004: 41), en la maquinaria de institucionalización de la explosión posmoderna que tuvo efectos claramente liberadores, pero que puede ejercer otros de dominio. ${ }^{3}$ Cuando no se atiende a las dimensiones prácticas, se corre el riesgo de idealizar románticamente algunas propuestas (Kaplan, 1987: 197) o de invisibilizar nuevas relaciones de poder, paradójicamente, con propuestas que han tenido efectos subversivos. Por eso, como Foucault señaló acerca del psicoanálisis, la teorización feminista supone un permanente principio de inquietud, no muy reconocido académicamente, con efectos de interrogación y problematización constantes. Consideramos que también la obra de Foucault ha sido objeto de tal lectura; pero ha sido algo más, ha sido una aliada estratégica, una "caja de herramientas", una cartografía provisional de lo que llamamos nuestra época cuyas exploraciones se han esbozado de manera paralela, divergente, entrelazada, con puntos de contacto indudables con aquellas realizadas por la teoría feminista.

Voluntad política de transformación, pues, y conciencia de los efectos de poder que generan los discursos, también los feministas; esta última cuestión ha abierto un espacio de viva polémica en el seno del feminismo en relación con los efectos de reificación y homogeneización que implica el uso de la categoría mujer y la desatención a otros dispositivos de poder que afectan de manera diferenciada a las mujeres. Son las posiciones postestructuralistas las que dentro del feminismo han asumido de manera más intensa los desafíos de hacer converger presupuestos antiesencialistas, desestabilizadores de las categorías convencionales de pensamiento como la del sujeto moderno, con una voluntad específica de problematizar y combatir los efectos de dominio que la construcción de la diferencia sexual implica. A pesar del rechazo a determinaciones ontológicas se reconoce que, en las coordenadas sociohistóricas occidentales, el sistema sexo/género condiciona la inteligibilidad de los sujetos. Es un dispositivo que participa en su configuración mediante prácticas sociales reguladas.

${ }^{3}$ En relación con la práctica del socioconstruccionismo académico es interesante la puntualización y problematización que, planteadas de forma diferente, llevan a cabo Teresa Cabruja por un lado y Margot Pujal, por otro, en el monográfico de Política y Sociedad (Cabruja i Ubach, 2003; Pujal i Llombart, 2003). En otro orden de cosas, las resistencias que Rosi Braidotti señala contra la fascinación y la euforia derivadas de la dislocación de todo sujeto, subrayando la pertinencia de las consideraciones éticas y políticas en el "mercadeo fetichista de las diferencias" (Braidotti, 2004). 
Aun considerando las divergencias feministas, Foucault ha devenido en interlocutor privilegiado de gran cantidad de desarrollos teóricos y reflexiones acerca, precisamente, del poder, la dominación y la subjetividad. La magnitud y la audacia de los análisis foucaultianos acerca de los dispositivos de saber/poder o de los procesos de subjetivación, interpelan y son objeto de lectura crítica por parte de muchas autoras, que han utilizado sus herramientas o las han sometido, como Georges Canguilhem dijo, a sus propios "métodos de esclarecimiento, es decir, la genealogía y la interpretación" (Canguilhem, 1989: 12). Hay nudos de confluencia evidentes, como el ejercicio crítico en relación con las categorías fundamentales del pensamiento occidental, sus efectos políticos y el anhelo de transformación, sea más o menos escéptico, que atraviesa la propia reflexión teórica.

Consideramos, por lo tanto, que la obra de Foucault resulta de especial interés para la reflexión feminista, así como ésta, en su diversidad, resulta relevante para las propuestas analíticas de la operatividad del poder. Analizaremos a continuación espacios de confluencias y divergencias variadas, sin ninguna pretensión de sistematización de tales (des)encuentros ni de exhaustividad en la consideración de la obra foucaultiana o del pensamiento feminista. Foucault no pretendió establecer un sistema teórico cerrado, huyó reiteradamente de las pretensiones de totalidad que tales formulaciones destilan, rechazó las síntesis homogeneizadoras y se desplazó de manera no lineal sino compleja y recurrente por espacios de análisis que contemplaban no tanto los conceptos y las nociones de poder, saber o sujeto, sino los procesos y relaciones poliédricas entre ellos. La riqueza de la reflexión feminista es, a su vez, difícilmente domesticable bajo una presentación esquemática donde la disparidad se recubra. Ni síntesis ni totalizaciones: sólo pretendemos apuntar algunos de los destellos reflexivos y de las intensidades políticas que la elucidación mutua ha permitido. Un escenario, como en la fábula, en el que las diferencias no se contraponen sino que estallan e incitan a seguir pensando.

Las confluencias y divergencias no se dan de manera unánime; los asuntos y formulaciones implicados en ellas se sitúan, además, en niveles de concreción muy diversos; en ocasiones, incluso, aquello que resulta conflictivo para una lectura feminista, es muy pertinente para otra, simplemente porque su nivel de generalidad se ha matizado de otra manera. La propia "extraña coherencia" (López Álvarez y Muñoz, 2000: 22) o la "continuidad en la discontinuidad" (Ibáñez, 2001: 122) de las formulaciones foucaultianas, junto con la heterogeneidad de los desarrollos feministas, generan lecturas divergentes, que se interpelan mutuamente y que establecen conexiones móviles entre ellas. Como veremos a continuación, aquello que para algunas es una confluencia entre los dos espacios teóricos, para otras es un desencuentro. Aquello que es recibido como una formulación pertinente para la teoría feminista como, por ejemplo, la analítica del poder disciplinario y la producción de cuerpos dóciles, que algunas teóricas consideran de excepcional interés (Bordo, 1993), es considerado por otras como una limitación que impediría un uso político emancipatorio por parte de las mujeres (McNay, 1992).

Quizá tales ambivalencias deriven de los planos diferentes en los que se sitúan las lecturas, priorizando el análisis de los procesos de dominación, por un lado, o las propuestas subversivas, por otro. Quizá la ambivalencia exija una más afinada consideración, precisamente, de la mutua implicación del poder y la libertad, de la sujeción y de la agencia, tomando en consideración específica la cuestión del cuerpo sexuado y la constitución de la diferencia sexual.

Quisiéramos realizar un último apunte. En ocasiones aparece en la discusión teórica un tipo de crítica falaz que consiste en formular reproches dando por supuestas pretensiones que quien ha actuado/pensado/escrito no tiene. Ante una obra compleja y abierta puede reprocharse, 
precisamente, su incompletud si se parte de una exigencia implícita de totalidad. Pero esas eventuales carencias resultan en otras lecturas espacios potenciales de reflexión. Hay rechazos y reproches que son el negativo de una ilusión: la posibilidad de una obra teórica que vea todo, y que lo vea desasiéndose de las contingencias históricas que la marcan. Ninguno de los polos del diálogo aquí señalados -los pensamientos feministas, la obra de Foucault- pretende establecer totalidades o fundamentos necesarios; ninguno, y quizá es más importante, pretende situarse fuera de la superficie histórica y social en la que se inscribe y, de alguna manera por ello mismo, combate.

La escritura de Foucault es detallada y aguda, despiadada por su claridad desplegada sobre espacios complejos. Minuciosa, pero nunca hermética. Arriesgada y feroz, pero siempre cautelosa. Resuenan en sus textos la voluntad de deliberación, de contraste, de elucidación mutua que la producción académica oficial suele pulverizar. No podía ser de otra manera para un pensamiento móvil que proclama la historicidad y el antiesencialismo de sus análisis. No sólo eso: también la imposible exterioridad con respecto al poder de cualquier posición filosófica, teórica, política. Incluso de aquellas propuestas de resistencia. Estos elementos ejercen una constante incitación teórica ${ }^{4}$ para quien reconoce y prioriza las dimensiones políticas del conocimiento. A pesar de la opinión de Manuel Cruz de que las incitaciones foucaultianas "no parecen haber dado lugar a líneas autónomas y fecundas de reflexión" (Cruz, 2002: 359) consideramos que, por lo menos en relación con la teoría feminista, sí puede hablarse de un espacio intenso de discusión y de líneas de desarrollo y análisis autónomas, como pueden ser los trabajos llevados a cabo por los denominados "feminismos foucaultianos". De hecho, el feminista es uno de los ámbitos en el que la crítica a las formas de individualización se ha enlazado con la promoción de nuevas formas de subjetividad.

\section{Leyendo a Michel Foucault}

La obra de Foucault ha sido objeto de muy diversas lecturas feministas. Estas abarcan desde el rechazo manifiesto de algunas teóricas hasta la alianza estratégica y fructífera que han elaborado los feminismos foucaultianos, que encuentran en su obra "una fastuosa caja de herramientas que ofrece conceptos brillantes, instrumentos operativos e incitaciones originales" (Perrot, 1997: 104). Pasando por la consideración de que podría ser, no un buen marido, sino un "buen amante ocasional" para la práctica feminista (Nancy Fraser, 1989).

Como muestra Michèle Perrot, la aparición de las mujeres en la obra de Foucault se da a través de figuras ambivalentes, mediante presencias esquematizadas y poco problematizadas (Perrot, 1997). La madre de Pierre Rivière, por ejemplo, es según él un personaje absolutamente "enigmático"; lo cual resuena como una referencia a la feminidad de hondas raíces androcéntricas. La exasperante Mme. Jourdain, que nos aparece en Historia de la locura, representa la figura, asimismo, de una esposa y madre que ejerce simplemente un poder disciplinario encuadrada en esa familia que desde el siglo XVII imanta un ejercicio de poder creciente, en el desarrollo de la gubernamentalidad, como institución que regula y que combate el desorden.

A partir de Historia de la sexualidad las mujeres adquieren otro estatuto y densidad como objeto de análisis. El cuerpo femenino aparece en adelante como un espacio estratégico, blanco de ejercicio

\footnotetext{
${ }^{4}$ Tanto Ibáñez como Cruz han hablado de incitaciones foucaultianas. (Ibáñez, 2001) en el capítulo "Incitaciones foucaultianas" y (Cruz, 2002: 359).
} 
del biopoder y sujeto a un proceso progresivo de objetivación y de control por parte de los discursos médicos y psicológicos. Es lo que denomina histerización del cuerpo de la mujer. La medicalización minuciosa del cuerpo femenino, como señala en La Voluntad de saber, se vincula asimismo con la responsabilidad exigida a las mujeres de velar por la salud de los niños, la solidez de la institución familiar y la salud de la sociedad (Foucault, 1976b). Foucault va otorgando progresivamente importancia y entidad a las regulaciones de las posiciones masculinas y femeninas como relaciones de poder; incluso lo considera como tema de análisis para uno de los futuros volúmenes de la historia de la sexualidad; proyecto que abandonó y recondujo posteriormente:

"Se ha intentado durante mucho tiempo fijar a las mujeres a su sexualidad. "No sois nada más que vuestro sexo", se les decía desde hace siglos. Y este sexo, añadían los médicos, es frágil, casi siempre enfermo y casi siempre causa de enfermedad. "Sois la enfermedad del hombre". Y este movimiento muy antiguo se precipitó hacia el siglo XVIII desembocando en una patologización de la mujer: el cuerpo de la mujer llega a ser el objeto médico por excelencia. Intentaré más adelante hacer la historia de esta inmensa "ginecología" en el más amplio sentido del término". (Foucault, 1977c: 261).

Considera Foucault que tal patologización del cuerpo femenino adquirió su mayor intensidad a finales del XIX y principios del XX y señala a Charcot como uno de los escenificadores de tal régimen discursivo, con su incitación espectacular de síntomas histéricos en la Salpêtriere. Sesiones a las que asistió Freud y de las que habría heredado esa consideración patológica del sexo femenino. Esta es una de las razones que esgrime Foucault para desdeñar la teoría sexual del psicoanálisis, aunque reconozca la aportación de Freud en relación con el estudio de los procesos inconscientes (Foucault, 1977a).

En el desarrollo de su trabajo, el impacto de nuevos tipos de lucha política como la feminista o movimientos homosexuales, que politizan el espacio identitario y cotidiano, fue intenso y es integrado en sus reflexiones acerca de la resistencia y de los dispositivos de poder. "Las relaciones entre hombres y mujeres, dirá, son relaciones políticas, no podemos cambiar la sociedad más que a condición de cambiar estas relaciones" (Foucault, 1978: 473). Junto con su experiencia política en el GIP, esto le hace dirigir sus análisis a las prácticas sociales, discursivas y no discursivas, parejas a la elaboración de la noción de dispositivo. De hecho, Foucault reconoció que las nuevas luchas políticas articuladas en torno y después del 68 le permitieron explicitar una analítica del poder que solo latía implícita en sus obras anteriores:

"Sólo se pudo empezar a realizar este trabajo a partir del 68, es decir, a partir de luchas cotidianas y realizadas por la base, con aquellos que tenían que enfrentarse al poder en los eslabones más finos de la red de poder. En ese espacio apareció la cara concreta del poder y, al mismo tiempo, mostró la posible fecundidad de estos análisis del poder para darse cuenta de las cosas que habían permanecido hasta entonces fuera del campo del análisis político." (Foucault, 1977d: 146).

El término microfísica señalará el alcance capilar que las relaciones de poder adquieren en el campo social y, por lo tanto, las luchas cotidianas, ésas que impugnan y contestan, por ejemplo, las formas de amar, el modo en que se reprime la sexualidad o la prohibición del aborto, son explícitamente políticas (Foucault, 1973: 428). 
Más allá de estas pinceladas, que hablan así mismo de la actualidad en la que él estaba inserto, su obra provee de herramientas y estrategias para abordar la constitución de las subjetividades y las prácticas de poder en las que se configura y se reactualiza el género; para historizar estos dispositivos y abordar las especificidades y transformaciones que presentan, eludiendo así la construcción discursiva naturalizadora y homogeneizadora de las mujeres, así como posibilitando la consideración de las articulaciones del dispositivo de género con otros dispositivos generadores de desigualdad como los económicos y de clase.

Desde los años 80, ha sido fundamentalmente el feminismo norteamericano el espacio de recepción y elaboración de una línea foucaultiana de análisis que ha acentuado dos elementos claves. Por un lado, la productividad de las tecnologías disciplinarias y normalizadoras, vinculadas al dispositivo de género, que producen, regulándolos, los cuerpos femeninos. Así lo muestran los análisis sobre la vergüenza, la anorexia, la agorafobia o la presión estética de Sandra Lee Bartky y Susan Bordo (Bartky, 1988, 1990; Bordo, 1988, 1993). Por otro lado, los análisis de tales tecnologías en conjunción con los saberes que han generado una sobredeterminación naturalizada del sujeto mujer, en diversos desarrollos teóricos que proliferaron a final del siglo XIX en occidente y han persistido durante el siguiente.

Más recientemente ha sido la cuestión de los modos de subjetivación y las prácticas de sí la que ha recibido atención. La historia de la subjetividad que Foucault plantea provee de elementos para pensar, no solo la operatividad del saber/poder, sino la relación que éstos establecen históricamente con las formas en las que un individuo es interpelado y se reconoce como sujeto, por ejemplo hombre o mujer, insertándose en una red normativa inevitable. Más allá de la descripción de los códigos, Foucault disecciona esas formas subjetivas, esas prácticas subjetivas en las que se juega la relación de una consigo misma y con las prescripciones sociales vigentes. Los códigos pueden permanecer, pero las formas de relación y de interpelación de éstos pueden variar, e incluso permitir un proceso subjetivo de autoconstitución o desprendimiento de identidades normativas (déprise de soi) en el que Foucault situaría la eventualidad de una práctica de libertad. De hecho, la práctica feminista ha sido un proceso efectivo de transformaciones subjetivas y de creación de nuevas formas de vida. En las últimas reflexiones de Foucault acerca de la ética, de la libertad y del coraje de la verdad en el seno de los modos de subjetivación, ha sido celebrada la pertinencia que ofrecen para la resistencia y la política feminista.

No obstante, han sido abundantes las matizaciones y las críticas a ciertos aspectos de su obra. La consideración más extendida, incluso por aquellas autoras que lo utilizan, es que sus planteamientos son androcéntricos: desde la consideración de que aquellos cuerpos dóciles de Vigilar y castigar eran cuerpos masculinos, hasta la constatación de que todo su último trabajo se sustenta en el estudio de una problematización de los placeres o de la existencia: la que se daba en la antigüedad grecorromana, en la que dominaba una moral viril que excluía a las mujeres y a los hombres no libres del ejercicio de la reflexión, de la autocreación y del cuidado de sí. Un cierto descuido del dispositivo de construcción de la diferencia sexual y de la especificidad de la sujeción de los sujetos mujeres parece atravesar su obra. No obstante, esta constatación solo se convierte en reproche cuando se presupone una totalización teórica de la que siempre intentó zafarse. Nada impide estirar los hilos, seguir tejiendo, bosquejar nuevas inquietudes y señalar lagunas sobre las que precipitarnos para seguir pensando.

Se han apuntado diferentes tendencias en la lectura feminista de Foucault. Las clasificaciones son diversas: desde la distinción entre feminismos foucaultianos y otros que atienden a aspectos de su 
obra -fundamentalmente la crítica al esencialismo y la analítica del poder- pero como a la de cualquier otro pensador crítico (Romero Pérez, 1996); la distinción entre las autoras que han recogido específicamente la noción de poder disciplinario para analizar su cristalización en el cuerpo femenino y aquéllas que se han centrado en la noción de resistencia para realizar formulaciones pragmáticas feministas (Sawicki, 1991); o las distinciones entre quienes han priorizado el uso empírico de las ideas foucaultianas y aquellas que han destacado las formulaciones teóricas para incorporarlas al sistema epistemológico feminista (Martín González, 2003).

Consideramos que estas clasificaciones, como todas, aportan inteligibilidad operativa pero pueden ser problemáticas. Respecto a la primera distinción, pensamos que los feminismos foucaultianos casi siempre sostienen una distancia crítica y deliberativa; en relación con la segunda, se puede plantear que cada vez más se utiliza un enfoque que contempla conjuntamente las nociones de sujeción y resistencia, como la obra, inabarcable aquí, de Butler; por último, respecto a la tercera, que los usos empíricos siempre implican un cierto nivel de elaboración teórica.

Las nociones foucaultianas utilizadas por algunas autoras son objeto de crítica por parte de otras, que a su vez valoran lo que otras consideran elementos inadecuados para la teoría feminista. Por ejemplo, en función de su pertinencia para la política feminista, Susan Bordo rechaza el sujeto del "último Foucault" puesto que difícilmente puede hablarse de agencia y resistencia cuando el análisis de las estrategias disciplinarias ha revelado estas últimas como extremadamente eficaces, sobre todo en relación con el cuerpo de las mujeres (Bordo, 1993: 194). A su vez, Lois McNay celebra, precisamente, ese "último" Foucault considerando que libera y contempla las posibilidades de agencia de ese sujeto que no era sino un cuerpo dócil en sus anteriores trabajos (McNay, 1992, 2000). La complejidad de la obra del autor francés y la densidad y divergencias de las líneas feministas dificulta una demarcación límpida en la caracterización de las lecturas foucaultianas.

Consideramos más interesante, por tanto, explorar las diversas confluencias y críticas que han ido emergiendo en este proceso de interlocución y elucidación múltiple, sin necesidad de establecer clasificaciones de las lecturas; destacando, por el contrario, intensidades, matizaciones y reelaboraciones. Comencemos, tentativamente, con las confluencias.

\section{Espacios de confluencia}

\section{Analítica del poder}

Existe cierto acuerdo en considerar la analítica foucaultiana del poder de gran utilidad, en tanto sitúa su operatividad, a través de un ejercicio heterogéneo y práctico, en aquellos espacios habitualmente excluidos de lo político y en la regulación de relaciones y prácticas cotidianas que recorre la organización de tiempos y espacios. Por otro lado, las complejas relaciones de los dispositivos de saber/poder favorecen una mirada crítica hacia las narrativas canónicas y discursos cotidianos y académicos. Además, esta analítica, que escruta tal ejercicio en la conformación de cuerpos e identidades, es un potente utillaje contra la naturalización de las diferencias producidas.

Es innegable, por tanto, que aquello que el eslogan feminista "lo personal es político" planteaba confluye con la reconsideración que Foucault realiza acerca de las formas de pensar las relaciones de poder. Su paradigma estratégico subraya las limitaciones que el paradigma jurídico entraña, en 
tanto este último considera la ley como elemento fundamental y localiza el poder en instancias determinadas desde las que descendería. En contra de tal esquema, Foucault señala repetidamente que el poder no es ni una propiedad ni una sustancia ni se localiza exclusivamente en un foco determinado. La operatividad y la productividad de las relaciones de poder penetra y teje las fluctuantes mallas de lo social y constituye, incluso, la microfísica de lo genuinamente político (Pardo, 2000: 43). Su obra, por tanto, subraya tal operatividad en relaciones y espacios "micro", al tiempo que sitúa en ellos la propia constitución de los sujetos. No hay sujetos preconstituidos antes de su inserción en las mallas del poder. Los procesos de subjetivación aludirán a esta productividad de identidades y de formas de sujeto históricas y contingentes.

Por otro lado, su crítica al economicismo y a algunos de los presupuestos de las teorías marxistas confluye con la que el movimiento feminista ha realizado por su incapacidad de analizar las relaciones sociales de reproducción y la subordinación a la que relega a las luchas que devienen secundarias por vincularse con efectos supraestructurales. Frente a la validez o no del análisis marxista para explicar la opresión de las mujeres, que no abordaremos aquí, la analítica del poder foucaultiana supone una sacudida desafiante, cuya focalización en las microprácticas sociales la hace potencialmente valiosa para el pensamiento feminista.

El poder concebido como dispositivo estratégico y heterogéneo en el que las prácticas múltiples e inmanentes producen, regulándolo, el ámbito de lo social, resulta pertinente para el abordaje de la configuración de los sujetos sexuados en relaciones de poder que atraviesan espacios múltiples y cuya experiencia histórica excede las dimensiones racionales o voluntaristas. $Y$ es interesante porque permite llevar a cabo un análisis de tales formas subjetivas atendiendo a sus características sedimentadas y corporeizadas sin recurrir a elementos esencialistas, sino a los procesos históricos que producen tales ontologías. La genealogía, esa forma de historia que intenta dar cuenta de la constitución de objetos y sujetos, no necesita referirse a un sujeto trascendente en relación con el campo de los acontecimientos, pero permite la consideración de las regularidades y de los efectos obstinados de tales constituciones. ${ }^{5}$ Algo que confluye con un análisis de las condiciones de las mujeres sin elementos esencialistas; algo que Judith Butler ha denominado "genealogía de la ontología de género" (Butler, 1990: 66). Siempre histórica y siempre situada, en donde la diversidad de procesos y su inscripción concreta eluda generalizaciones problemáticas de lo femenino; y, a su vez, no sea ciega al dispositivo de género como dispositivo de poder.

Destacamos, esquemáticamente, algunos elementos importantes de su analítica:

- La ubicuidad del poder, que alcanza también el ámbito corporal, estableciendo disposiciones y cursos de acción regulados, imbricando en ellos dimensiones afectivas y no conscientes, tal como su análisis seminal de los dispositivos disciplinarios y normalizadores de Vigilar y castigar señala. En las mallas del poder se juegan también los deseos y los placeres, "se crean los deseos y se provocan

\footnotetext{
${ }^{5}$ Al respecto Foucault señala que "no hay que hacer con el acontecimiento lo que se hizo con la estructura. No se trata de colocarlo todo en un plano, que sería el del suceso, sino de considerar detenidamente que existe toda una estratificación de tipos de acontecimientos diferentes que no tienen ni la misma importancia ni la misma amplitud cronológica, ni tampoco la misma capacidad para producir efectos." (Foucault, 1977d: 145) (el énfasis es nuestro).
} 
los placeres (...) y ahí es necesario sorprenderlo -el poder-y elaborar un análisis" (Foucault, 1975: 772)

- Más allá de sus formas represivas, la productividad del ejercicio del poder, tanto desde sus operaciones de demarcación y construcción discursiva de los objetos/sujetos como de las prácticas con ellas interrelacionadas, que establecería procesos de subjetivación específicos e históricos. Los discursos acerca de la naturaleza de las mujeres y prácticas de normalización y disciplina son especialmente relevantes, como veremos más adelante, en la producción de cuerpos y subjetividades femeninas "adecuadas".

- El carácter multiforme del poder que conduce a pensar también en otros dispositivos que interactúan con aquellos que construyen la diferencia sexual de una manera determinada y que permiten, precisamente, atender a las diferencias insoslayables que se dan entre las mujeres.

- La consideración de la resistencia como elemento intrínseco al ejercicio del poder. Si el poder "opera sobre un campo de posibilidad en el que se inscribe el comportamiento de los sujetos activos, incitando, facilitando y dificultando, restringiendo absolutamente en ocasiones límites" (Foucault, 1982: 237), nunca determina completamente tales posibilidades puesto que, en tanto ejercicio temporal y heterogéneo, siempre están los cursos de acción abiertos a efectos inesperados o articulaciones nuevas. La consideración de la resistencia inherente a cualquier relación de poder alienta la posibilidad de subversión y de transformación.

Esta analítica del poder, por tanto, nos sitúa en un escenario en el que atender a esa tensión inherente entre la sujeción y la agencia que conforma reiteradamente la corporalidad y las formas subjetivas sin determinarlas, pero sin permitir un espacio imaginario de absoluta libertad o exterior a las condiciones históricas y sociales de su emergencia. Tensión que, de manera diversa y compleja, ha sido abordada explícitamente por el pensamiento feminista posestructuralista (Butler, 1997b; De Lauretis, 2000; Braidotti, 2004).

\section{Formaciones discursivas y límites de inteligibilidad}

La inserción de los sujetos en juegos de verdad es una cuestión que Foucault aborda ya desde su tesis sobre la Historia de la locura y que, de manera un poco distinta, plantea en Las palabras y las cosas. Tanto las demarcaciones discursivas de la locura como la objetivación del "hombre" que las ciencias humanas acometen en el siglo XIX, implican esta compleja relación y producción de las formas de sujeto en juegos de verdad históricos. En la Arqueología del saber propone esclarecer metodológicamente sus obras anteriores y las reglas de formación de los discursos, impugnando clasificaciones convencionales y modelos acumulativos de producción de los saberes. Distingue la arqueología del análisis de la lengua -sistema finito que autoriza un conjunto infinito de enunciados posibles- y la considera un análisis centrado en el campo limitado de los enunciados históricamente producidos, considerando su materialidad y su especificidad, en tanto hechos y acontecimientos discursivos (Foucault, 1969b). Desde esta perspectiva analítica, además, considera que es imposible describir completamente nuestro propio archivo -el sistema general de la formación y la 
transformación de los enunciados- puesto que hablamos desde el interior de sus reglas (Foucault, 1969b: 171).

Diversos autores han subrayado la dimensión pragmática de la arqueología de Foucault y han explorado las conexiones de ésta con las obras de Ludwig Wittgenstein, John L. Austin o John Searle (Dreyfus \& Rabinow, 1984; Larrauri, 1999). El mismo Foucault reconoció esta coincidencia en el análisis de la dimensión performativa de los discursos en la que los términos enunciado y acto de habla aparecen muy próximos; pero subraya que su análisis del discurso como estrategia está más explícitamente vinculada a los contextos históricos y, por tanto, relacionada con prácticas sociales y relaciones de poder (Foucault, 1974). Los discursos a los que atendió principalmente, los de las ciencias humanas, están insertos en regímenes de veridicción históricos, una política de la verdad que configura aquellos objetos de los que habla. Las prácticas discursivas han establecido, además, complejas relaciones circulares con otras prácticas, como las disciplinarias, nutriéndose mutuamente.

Con la emergencia de las ciencias humanas, el sujeto es objetivado como individuo con funciones de diversos tipos que implican la posibilidad de determinar normas de ajuste a tales funciones. Las normas operan como reglas naturales que indican si el funcionamiento de los individuos es adecuado o patológico. Con su dimensión positiva y productiva, la norma regula y se vincula al funcionamiento de todo el cuerpo social. Y la feminidad ha sido objeto de enfática construcción normalizadora y normativa en la que la función reproductiva y biológica ha sido, y sigue siendo, un elemento fundamental de la feminidad normal. La relación entre saberes y prácticas disciplinarias, analizada genealógicamente, ha resultado para muchas autoras un interesante abordaje de la conformación del sujeto "mujer" en los discursos médicos, psiquiátricos y educativos y de las prácticas institucionales con ellos relacionadas, como veremos a continuación.

La función performativa de los discursos identitarios y la operatividad productiva y regulativa de las nociones de sexo y género ha sido abordada desde hace años por numerosas autoras de cuya totalidad no podemos dar cuenta. Los límites de inteligibilidad que entrañan han sido específicamente explorados por Judith Butler para denunciar las (im)posibilidades de inteligibilidad social en una época determinada. Según ella, las categorías hombre y mujer ejercerían una operación constructiva y violenta ineludible. Problematizando tal ejercicio impensado y "natural" ha subrayado los límites de inteligibilidad de lo humano en nuestro contexto, que pasa por la construcción de mujeres y hombres, con un sexo o género con características concretas, dejando fuera un espacio abyecto e invisible al que se repudia a aquellos que subvierten tal ordenación discursiva y práctica (Butler, 1990; Butler, 1997a).

Por otro lado, también se ha vinculado de manera similar el análisis de las formaciones enunciativas con la violencia simbólica y la corporeización de sus efectos, subrayando la potencialidad política de las propuestas de reinvención que el pensamiento de la diferencia sexual plantea (Gómez, 2004; Larrauri, 1996).

\section{La verdad del sexo}

Tal como expresó Foucault en el primer volumen de Historia de la sexualidad, "determinada pendiente nos ha conducido, en unos siglos, a formular al sexo la pregunta acerca de lo que somos" (Foucault, 1976b: 96). Esta incitación discursiva y proliferación de prácticas para decir la sexualidad que, con su doble faz totalizadora e individualizadora -vinculada al ejercicio del biopoder y del poder pastoral-, se ha ido enredando en prácticas institucionales y discursos científicos para gestionar la 
vida, ha dado lugar a distintas tecnologías normalizadoras/ correctoras del cuerpo (individual/social) y de la sexualidad. $\mathrm{Y}$ han sido ampliamente estudiadas por autoras feministas tanto en su vertiente disciplinaria como en su dimensión discursiva-científica. Esta última se ha vinculado con el análisis de disciplinas como la sexología (Caplan, 1987), la medicina y la biología (Ehrenreich y English, 1990; García Dauder y Romero Bachiller, 2004), entre otras.

La naturalización de la sexualidad y el sexo es detalladamente abordada por Foucault:

"La sexualidad se definió "por naturaleza" como: un dominio penetrable por procesos patológicos, y que por lo tanto exigía intervenciones terapéuticas o de normalización; un campo de significaciones que descifrar; un lugar de procesos ocultos por mecanismos específicos; un foco de relaciones causales indefinidas, una palabra oscura que hay que desemboscar y a la vez, escuchar." (Foucault, 1976b: 86).

Esta retórica que ha gestionado la economía de los discursos, ha sido identificada por el pensamiento feminista como uno de los principales dispositivos de subordinación de las mujeres: esa "palabra oscura" que se incitaba a confesar, tal como dice Foucault, era ya una verdad enunciada de partida. En relación con la construcción de lo femenino, ese proceso parece haber sido históricamente más intenso: la verdad describía a las mujeres por su naturaleza carnal y su función reproductiva; incluso, en muchos discursos históricos tanto científicos como filosóficos, se establecía para los sujetos mujeres menos una posibilidad de indagación obstinada de la verdad vinculada a su sexo, cuanto una sobredeterminación "naturalizada" de éste. La objetivación de los individuos y los procesos de subjetivación quizá no han respondido, desde una perspectiva de género, a las mismas tecnologías del poder; quizá la existencia de tecnologías específicas, que no monolíticas ni invariables, en la constitución de subjetividades femeninas sustenten lo que algunas autoras han señalado: que los procesos de subjetivación se dan en un continuum en el que algunos sujetos son menos sujetos que otros (o están más sujetos que otros); es decir, habría una gradación en la configuración de ser/estar sujeto. Con las mujeres, en los procesos históricos, se habría dado una objetualización más intensa (Nussbaum, 1999) ${ }^{6}$.

Esta reflexión podría relacionarse con la relación, que interesó a Foucault durante sus últimos años, entre las técnicas de dominio que moldean la conducta de los individuos y objetivan al sujeto y las técnicas de sí que permiten a los individuos efectuar solos o con ayuda de otros algunas operaciones sobre su modo de ser. Quizá la construcción de los individuos como diferenciados según el sexo y con efectos de desigualdad se vincule con tecnologías específicas de género que restringen y particularizan las técnicas de sí que los sujetos mujeres se hallan en condición de llevar a cabo. Cuando abordemos el androcentrismo de Foucault indagaremos en las posibles explicaciones y derivas de esta idea.

La objetivación discursiva de las mujeres mediante la naturalización del sexo y las técnicas vinculadas a ello, por tanto, han sido mecanismos de constitución de sujetos (más) subordinados en determinados contextos históricos; así lo ha denunciado la práctica feminista mediante los cuestionamientos de las verdades científicas acerca de las particularidades e inferioridades

\footnotetext{
${ }^{6}$ Teresa De Lauretis también analiza esta idea en relación con la exposición que hacen de ella tanto Simone de Beauvoir como las lecturas feministas del marxismo (De Lauretis, 1990).
} 
femeninas, la impugnación de una biología que fuera destino, o la exploración más reciente de los discursos reproductivos (Sawicki, 1991). Aunque esta confluencia con Foucault es reseñable, también lo es, simultáneamente, la crítica que se le ha dirigido; puesto que, a pesar de haber desentrañado complejos dispositivos de construcción de la sexualidad y gobierno de la vida, no ha visibilizado aquellos que de forma específica ejercían un plus de violencia en función de una mayor naturalización y, por lo tanto, mayor restricción de posibilidades en los procesos de individuación. Algo que derivaría, según algunas autoras, de la no problematización del sistema sexo/género en sus elaboraciones sobre el biopoder (Rodríguez Magda, 1999).

Por último, quisiéramos señalar el uso prolífico del análisis foucaultiano de la sexualidad que concibe a ésta como los efectos producidos en cuerpos, comportamientos y relaciones sociales, y no como algo natural ya esencial de los seres humanos. Creemos que a partir de esta perspectiva se han desarrollado análisis y propuestas teóricas muy importantes que desplazan el término sexualidad hacia el de género. La consideración del género como "dispositivo" o "tecnología" constituye, tanto en su dimensión de análisis práctico como de elaboración teórica, una de las más interesantes y sugerentes aportaciones de la teoría feminista, por ejemplo, en las obras de Butler y de Teresa de Lauretis.

\section{Estados de dominación}

Las relaciones de poder que atraviesan el campo social implican la consideración de la/s resistencia/s. Pero las relaciones de poder, móviles y reversibles, pueden llegar a fijarse de manera que los márgenes de acción estén extremadamente limitados. A tales situaciones denominará Foucault estados de dominación. En ellos, las relaciones de poder son perpetuamente asimétricas. Para ejemplificarlas, señala la estructura conyugal tradicional de los siglos XVIII y XIX en la que "no se puede decir que sólo estaba el poder del hombre: la mujer podía hacer toda una serie de cosas: engañarlo, sisarle dinero, rechazarlo sexualmente. Sin embargo, ella sufría un estado de dominación en la medida que todo eso no constituía al final más que un cierto número de argucias que no llegaban jamás a dar vuelta a la situación" (Foucault, 1984b: 720-21).

En los estados de dominación es difícil que las resistencias sean efectivas o puedan multiplicarse y establecerse así estratégicamente. En tales situaciones los procedimientos dispersos, heteromorfos y locales de poder son transformados por estrategias globales (Foucault, 1977b). Foucault no profundiza en las implicaciones decisivas que tales situaciones plantearían para una eventual transformación, aunque sí indique la necesidad, en tales casos, de procesos de liberación. De todas formas, el desarrollo de la noción de gubernamentalidad desplaza la consideración fundamentalmente microfísica del poder a una consideración más exhaustiva de las formas de gobierno, incluyendo formas centralizadas junto a las que se dan en los ámbitos no regulados directamente por instancias de poder explícitas. Esta noción de gubernamentalidad parece ir sustituyendo en sus análisis a las referencias al biopoder (Beaulieu, 2004) y especificando de manera histórica -en Occidente- la integración de diversas técnicas de dominación y técnicas de sí (Foucault, 1988).

Tal como Jana Sawicki señala, esta atención a la conjunción móvil de estrategias diversas permitió mostrar a Foucault cómo las relaciones de poder en diferentes niveles sociales hacen posible efectos globales de dominación tales como clase o poder patriarcal, sin tomar estas unidades teóricas como sus puntos de partida (Sawicki, 1991). No obstante, el rechazo explícito de Foucault a 
considerar una estructura binaria de dominantes y dominados, es uno de los elementos que más críticas ha suscitado por parte de algunas lecturas feministas, como veremos más adelante.

\section{Técnicas de sí y procesos de autocreación}

Las técnicas de sí, "esas prácticas inscritas en la actualidad histórica que aluden a las formas y modalidades de relación consigo mismo mediante las que el individuo se constituye y se reconoce como sujeto" (Foucault, 1984a: 12), serán el objeto de reflexión de sus últimas obras. Su intento de comprender cómo se había constituido la experiencia de la sexualidad en las sociedades occidentales modernas se desdibuja a medida en que avanza. Se densifica y se desplaza hacia una genealogía del sujeto occidental abierta a nuevos elementos de estudio. Las técnicas de sí son las operaciones que los individuos pueden efectuar sobre sí mismos -y son incitados a efectuar en función de los contextos sociales a los que pertenezcan- para transformarse, modificarse o lograr algún tipo de estado de perfección (Foucault, 1981a). Estas técnicas siempre se establecen en una superficie histórica y aluden a la dimensión activa de los individuos, pero nunca son algo que un individuo invente solo (Foucault, 1984f).

Tales técnicas son abordadas de manera genealógica y, por ello, su mirada se retrotrae progresivamente hacia periodos históricos más lejanos. La consideración del sujeto como forma permite la apertura a la consideración de diversas posibilidades de constitución histórica, también de esa que el individuo opera sobre sí mismo. Las técnicas de sí se vinculan pues con las formas que regulan esta autoconstitución e introducen una dimensión moral normativa. Del análisis de las técnicas que el cristianismo establece históricamente, el examen y la confesión fundamentalmente, en las que el sujeto es interpelado y obligado a decir su verdad interna, a confesarla interpretándola, Foucault retrocederá hasta el análisis de otras técnicas que, como las de la antigüedad grecorromana, establecen otros juegos de verdad en los procesos de subjetivación. Por ejemplo, en la Antigüedad, la verdad del sujeto no es algo que ya estuviera en su interior y que debiera ser descubierto, sino el efecto de un proceso, un ejercicio constante con uno mismo. Algo que permitía mayor autonomía e importancia de la reflexión, así como la problematización de lo que se es para dejar de serlo.

Sin ahondar en ello, se puede señalar que Foucault detalló cuatro ángulos principales en la consideración de las prácticas de sí y que exploran tanto las formas de vinculación del individuo con los códigos normativos como las posibilidades que ofrecen para la práctica de la libertad: la sustancia ética, el modo de sujeción, las técnicas o ejercicios específicos y la teleología (Foucault, 1984e). Dicho de manera esquemática, de su articulación variable aparecerán formas de inserción en los códigos asimismo variables: habrá modos de subjetivación orientados al código, y modos de subjetivación orientados a la ética. Es decir, las técnicas de sí pueden vincularse a un código explícito y hacerlo de forma unívoca o, por el contrario, responder a la problematización de la experiencia como un trabajo continuo sobre sí mismo, sin partir de una fórmula de mero cumplimiento de una verdad establecida e innegable -sobrenatural, científica, etc.-

El cuidado de sí, entendido como experiencia y como técnica que elabora y transforma esa experiencia (Foucault, 1981b: 213), se abre a la estilización y a la problematización de tal experiencia y ahí sitúa la posibilidad del ejercicio de prácticas de libertad. Éstas estarían, pues, vinculadas con las posibilidades de decidir, crear o experimentar formas de existencia. 
La analítica del sujeto que Foucault lleva a cabo más explícitamente en sus últimas obras es quizá el corpus teórico que más atención reciente ha recibido por parte de teóricas feministas. Confluyendo con la problematización, tanto de la noción moderna de sujeto como del rechazo de cualquier forma de éste, la teoría feminista ha abordado una comprometida y exhaustiva consideración del espacio de lo subjetivo. $Y$ en esta reciente y candente literatura, que muchas autoras sitúan en los noventa y en los primeros años de este siglo, se retoman las lecturas foucaultianas (Allen, 2004: 235).

Estas lecturas de las prácticas de sí han sido variadas. A pesar de algunas discrepancias, hay por parte de muchas autoras una valoración muy explícita de este último tramo de su obra en cuanto reconsideraría una dimensión de agencia obliterada en la noción de cuerpo dócil (McNay, 1992). Ese espacio de tensión establecido entre las configuraciones sociales y la posibilidad de crear formas de vida permitiría eludir asimismo una distinción simplificada entre dominantes y dominadas y restituir, en un análisis más complejo, la agencia de las mujeres dentro de constricciones sociales específicas y múltiples. Permitiría, también, atender a la multiplicidad de experiencias de las mujeres. Combinando la consideración de dispositivos variados de poder y la potencialidad creativa de las mujeres, se podrían contemplar de una forma no esquemática tanto las diversas situaciones de opresión como las diversas maneras de subvertirlas y modificarlas. Lois McNay considera que el trabajo de Foucault sobre la subjetividad, a pesar de que no considere los procesos de género -o quizá precisamente por ello-, es útil para la labor feminista porque, frente a otros pensadores postestructuralistas, Foucault evita la colonización de lo "femenino" que según ella marca el trabajo de Derrida o de Baudrillard (McNay, 1992).

La relación que establece Foucault entre la noción de prácticas de sí con la noción de gubernamentalidad, permitiría asimismo considerar esa maraña de fuerzas de poder que no residen en un aparato unificado de dominación, sino en una red de instituciones y procedimientos que emplean técnicas complejas para organizar las relaciones sociales y que pueden ser parcialmente modificadas. La interrogación radical de la identidad que realiza Foucault puede converger con la crítica feminista al esencialismo y retener al mismo tiempo, mediante la consideración de las prácticas de sí, la posibilidad de autocreación como elemento de resistencia política.

\section{Espacio de divergencias}

El pensamiento de Foucault ha sido calificado reiteradamente de androcéntrico; aunque siempre aludió a las relaciones entre hombres y mujeres como relaciones de poder, no llegó a explorarlas específicamente ni atendió este espacio de análisis. Muestra, en palabras de Butler, "una cierta indiferencia problemática respecto de la diferencia sexual" (Butler, 1990: 30). Señalaremos a continuación las reflexiones que esta despreocupación ha podido suscitar.

\section{(In)adecuación para una política feminista}

Foucault aborda la cuestión ética en su última etapa al considerar que nos constituimos en agentes morales en función de prácticas de naturaleza profundamente histórica y contingente. Su pregunta sobre las prácticas de sí antes del cristianismo le lleva de descubrir que las "éticas paganas" no diferían de éste tanto en el tipo de reglas de austeridad como en las formas de relacionarse con éstas. Se abre ahí el espacio a la reflexión ética, que se situará en relación con la subjetividad y con la libertad, siendo ésta la condición ontológica de la ética, por un lado, y presupuesto de las 
relaciones de poder. Como señala John Rajcham (1991: 111), "lo determinado históricamente nunca es históricamente necesario"; la libertad es otro nombre que habita las relaciones de poder y la contingencia de la producción histórica. Las problematizaciones, de esta forma, devienen éticas y políticas.

La problematización genealógica del "hombre de deseo" que realiza Foucault alcanza por tanto la reflexión ética. En sus últimos libros, los modos de subjetivación y la constitución de agentes morales son situados en el espacio de relación entre la ética y la verdad. Las prácticas de sí de la Antigüedad, como las técnicas de existencia o el cuidado de sí, se circunscriben, no obstante, a un modelo viril (tal como él mismo señala) sustentado sobre el eje actividad/pasividad, que se ocupaba de regular en función del tal eje la relación de uno consigo mismo y con los otros. La reflexión acerca del cuidado de sí y de las artes de la existencia se localizan en un modelo de sexualidad y placeres desigual, porque se refieren a una élite y porque no contempla la relación entre iguales ${ }^{7}$; modelo del que las mujeres, por supuesto, están excluidas. Realiza, por tanto, una exploración del vínculo entre ética y libertad, pero sin atender a la complejidad que introducirían en tal análisis la relación entre iguales y la responsabilidad derivada de ella, por un lado, así como los procesos de constitución de los sujetos que ocupan las posiciones de subordinación e inferioridad. Aunque interrumpida, su reflexión sobre la ética se inició explorando las prácticas -como el cuidado de sí- mediante las que, desde posiciones concretas, algunos sujetos varones se relacionaban consigo mismos, se constituían en sujetos morales en un contexto explícitamente desigual. La exclusión de lo femenino del ámbito de la reflexión no es analizada, simplemente apuntada:

"Ejemplo: el estatuto de las mujeres casadas les prohibía toda relación sexual fuera del matrimonio; pero sobre este 'monopolio' apenas se encuentra reflexión filosófica, ni preocupación teórica. En cambio, el amor con los muchachos era libre (con ciertos límites) y al respecto se elaboró toda una concepción de la moderación, de la abstinencia, del vínculo no sexual". (Foucault, 1984c: 671).

Lo que venimos de señalar, junto con su enfoque agónico del poder, que no contempla dualidades (dominantes, dominadas) de partida, lleva a decir a algunas teóricas feministas que su indiferencia al género da como resultado la imposibilidad de establecer una distinción colectiva que implique una cierta "localización" genérica del poder; su modelo difuso impediría ver un antagonismo operativo de partida, impediría nombrar una opresión que movilice políticamente. Las responsabilidades, aludiendo a las masculinas, se disuelven (Deveaux, 1994). Según algunas lecturas, toda su retícula analítica estaría ciega a una situación generalizada de opresión, la del colectivo femenino (Bartky, 1988) y dificultaría por lo tanto su reverso: el planteamiento de procesos de emancipación y empoderamiento femeninos. Así es como Toril Moi considera el efecto que tendría la asunción de los planteamientos foucaultianos:

"El precio por ceder a su discurso sobre el poder es nada menos que la despolitización del feminismo." (Moi, 1985: 95).

\footnotetext{
${ }^{7}$ En la entrevista realizada por Dreyfus y Rabinow, Foucault dice que "la moral de los Griegos era la de una sociedad esencialmente viril en la que las mujeres estaban "oprimidas", en la cual el placer de las mujeres no tenía importancia ". (Foucault, 1984e: 612).
} 
Además de esta crítica que reprocha no haber reparado en la dominación masculina (López Pardina, 2003: 210), Foucault ha sido criticado, asimismo, por la ausencia en su obra de un marco normativo en el que enraizar las propuestas políticas. Más allá de su fascinación por los hombres infames, de su disección brillante de las tecnologías disciplinarias o de las reflexiones acerca de las prácticas de sí mediante las que algunos varones se constituían a sí mismos en el ejercicio de una libertad que ya poseían en tanto figuras privilegiadas de las sociedades grecorromanas, más allá de eso la obra de Foucault no permitiría la elaboración de unos postulados normativos mínimos que permitieran articular, sustentándolas como un suelo firme y fértil, las luchas y las resistencias organizadas.

Ciertamente, Foucault fue extremadamente escrupuloso y huyó reiteradamente de ejercer una función de "intelectual universal". Otorgó, sin embargo, relevancia y protagonismo a quienes, de manera colectiva o individual, luchan o resisten. Quiso ser un "intelectual específico". No dar pautas éticas y decir a otros qué deben hacer, pero sí dotar, no obstante, de instrumentos y análisis específicos para la acción política.

No propone fundamentos correctos para la práctica política pero ello no impide las denuncias concretas y furibundas que salpican su obra. No dice qué debe hacerse, pero muestra la contingencia de lo que aparece como inevitable, intentado, por otro lado, rescatar las posibilidades de socavarlo. Qué sea concretamente aquello que hay que resistir o modificar resulta en sus textos una propuesta abierta y circunscrita a la actualidad histórica. Creemos que a lo largo de su obra late una propuesta crítica explícita que puede nutrir con su retícula teórica y analítica las prácticas que intenten transformar un orden dado:

"en lo que se nos da como universal, necesario, obligatorio ¿qué parte hay de lo que es singular, contingente y debido a constricciones arbitrarias? Se trata, en suma, de transformar la crítica ejercida en la forma de la limitación necesaria en una crítica práctica en la forma del franqueamiento posible". (Foucault, 1984d: 574).

A nuestro entender, su lectura no resulta en una desactivación de lo político; por el contrario, se pueden extraer de ella elementos para articularlo. Evita establecer principios trascendentes o absolutos. Para un pensador que ha privilegiado el carácter histórico de la crítica y de las luchas situadas, esto hubiera supuesto un cierto contrasentido. Creemos que sería problemático considerar que ejerce un efecto de despolitización; por el contrario, provee de sospechas y escepticismo hacia fundamentos o estrategias políticas monolíticas que pudieran re-crear algunas subordinaciones. Los fundamentos para la acción política, como Judith Butler ha subrayado reiteradamente, pueden ser contingentes: "que esos fundamentos existan sólo para ser cuestionados es el riesgo permanente de un proceso de democratización abierto. Rechazar esa disputa es sacrificar el ímpetu democrático radical de la política feminista" (Butler, 1998: 35).

De todas formas, podríamos sugerir algunos matices. Como señala Margaret McLaren, en el análisis de las tecnologías de normalización, Foucault critica al menos dos tipos diferentes de normas. Por un lado, normas universales vinculadas a justicia y derechos. Por otro, "normas sociales que prescriben conductas particulares y que categorizan a los individuos en grupos" (McLaren, 2004: 215). Quizá Foucault, aunque al final mostró posiciones diferentes a las que mantuvo a principios de los 70, no acabó de problematizar algo que para las mujeres, y para el movimiento feminista más específicamente, ha constituido un elemento fundamental de lucha -sobre el que también se han reificado posturas antagónicas y se han dibujado tensiones internas-: la cuestión de la igualdad, en abstracto, y la de la igualdad en derechos concretos. Porque, precisamente, ha sido en muchos 
momentos esta demanda de igualdad la estrategia para permitir distanciamientos de las identidades prescritas y la creación de formas de vida antes impensables. Aquí podríamos recordar la Antígona de Butler y ese mecanismo de citación que reconfigura performativamente una situación cuando el discurso del gobierno es dicho por quien no estaba legitimado a decirlo. Una "mímesis crítica" en la que las viejas palabras, desde una posición de enunciación distinta, pueden tener efectos transformadores (Butler, 2004).

\section{El androcentrismo de Foucault}

Son abundantes los apelativos que ha recibido la obra de Foucault en términos de mirada o construcción teórica androcéntrica. "Flagrante androcentrismo", dice Rosa María Rodríguez Magda (1999: 250). Según Susan Hekman (2004: 200), Foucault nunca examinó específicamente la subordinación de las mujeres o las fuentes de su subjetivación. Para Sandra Lee Bartky (1988), su análisis global reproduce el sexismo que es endémico a toda teoría política occidental. Incluso Lois McNay (1992:, 35) añade que la visión agenérica del cuerpo y la asunción de la sexualidad masculina como modelo de análisis le hace caer en la trampa universalista que teóricamente rechazaba su proyecto filosófico. A tal ceguera ante las diferentes tecnologías de género, Diana Fuss (1989: 107) la llama irónicamente su "voluntad de no saber acerca de las mujeres". No podemos saber nada acerca de esta voluntad, pero sí que pudo intuir su propia ceguera o dificultad de atender a elementos que operan en la configuración de la experiencia de las mujeres:

"Estos diversos tipos de represión han variado a lo largo de décadas, pero no puedo decir que haya encontrado diferencias fundamentales en lo que concierne a la mujer o al hombre. Pero yo soy un hombre". (Foucault, 1975: 770).

También hay quien ha planteado una genealogía de tal característica androcéntrica, señalando que el androcentrismo de Foucault tendría su origen en la no asunción y consideración de la obra de Margaret Mead, que conoció, y en una lectura sesgada de Marx (Romero Pérez, 1996).

La cuestión de las categorías y las calificaciones es algo incómodo. No resulta sin embargo descabellado considerar tal androcentrismo si lo vinculamos con los asuntos no problematizados en su obra, o con su desatención a determinados aspectos específicos de las relaciones de poder que han operado históricamente en las vidas de las mujeres. Sobre todo porque permiten, más que una confrontación, una matización y la fertilidad que otras o nuevas preguntan generan. Abordaremos esos elementos problematizados por las lecturas feministas en función de su carácter androcéntrico.

\section{Cuerpo dócil y masculino}

Como dice Rodríguez Magda (1999: 216) en relación con los análisis de las tecnologías disciplinarias de Vigilar y castigar, "no existen los cuerpos neutros y universales, por más que el sexo sea un constructo y la sexualidad una elección" y la diferencia sexual, construida en la medida que se quiera, es también un elemento que específicamente han regulado los dispositivos disciplinarios sobre y en los cuerpos. Foucault se habría referido, no obstante, "a un cuerpo neutro, por el que no hay que dejarse engañar, puesto que es un cuerpo masculino" (Le Blanc, 2004: 17). Braidotti (1991), asimismo, sostiene que Foucault nunca localiza el cuerpo de la mujer como el sitio de una de las divisiones más internas y operacionales en nuestra sociedad, y consecuentemente, también, una de las más persistentes formas de exclusión. La diferencia sexual, simplemente, no juega un rol en el 
universo de Foucault, donde la tecnología de la subjetividad se refiere a un sujeto "humano" desexualizado y general.

Esta es una de las limitaciones achacadas a los análisis de Foucault que más fructífera y sugerente ha resultado para la investigación feminista. La consideración de una "ceguera de género" en la reflexión acerca de las políticas disciplinarias sobre el cuerpo ha estimulado otros análisis más específicos sobre la disciplinarización del cuerpo de las mujeres. Entre estos análisis de las prácticas que lo someten y lo conforman destacan, como hemos señalado, los trabajos de Susan Bordo en torno a la agorafobia femenina durante los años 50 o a la anorexia actual, consideradas por la autora como la cristalización corporal de determinados imperativos culturales y prácticas de poder (Bordo, 1988, 1993). También Bartky $(1988,1990)$ ha considerado las prácticas estéticas actuales como prácticas disciplinarias de sometimiento femenino, destacando la dimensión activa de tal sometimiento, y una sugerente pedagogía disciplinaria de la vergüenza.

Al no abordar de manera específica las disciplinas y tecnologías normalizadoras que afectaban más concretamente a las mujeres, al aparecer éstas bajo la imagen de un cuerpo abstracto que era a su vez masculino, "deja en la oscuridad muchas experiencias importantes de poder específicas de las mujeres" (Deveaux, 1994: 232); tampoco Foucault atendió excesivamente —aunque tuvo el proyecto de hacerlo- a la proliferación de discursos sobre la feminidad ni a las prácticas disciplinarias con ellos entrelazadas, como la regulación de los tiempos/espacios vitales que producían y sujetaban a la población femenina durante el siglo XIX y XX en contextos occidentales: el encierro en el hogar o la docilización exhaustiva y patológica del cuerpo dispuesta desde preceptos médicos (uso de corsés y otras técnicas de restricción de la movilidad, sedentarismo obligado, etc.).

\section{Sexualidad}

La incitación productiva del dispositivo de la sexualidad que se despliega como el hilo argumental de la Historia de la sexualidad ha sido asimismo una cuestión discutida. ¿La "policía de los enunciados", la incitación discursiva a su proliferación, ha sido históricamente la misma para hombres y mujeres? ¿O esa historia del sujeto de deseo que Foucault planteaba, como producto de los dispositivos de poder que vinculaban verdad y sexo de forma creciente a partir del siglo XVI, olvidaba las particularidades vinculadas a la diferenciación sexual, sobre todo en los últimos siglos?

Que el hombre occidental se haya visto desde hace tres siglos apegado a la tarea de decirlo todo sobre su sexo, como Foucault escribía en la Voluntad de saber, plantea el interrogante de si esta intensa incitación ha funcionado exactamente así también para las mujeres. Algunas producciones discursivas sobre éstas quizá no han establecido de manera tan clara la vinculación entre deseo y sexo, sino que han construido una verdad del sexo y la sexualidad femenina sin un sujeto deseante, o con un sujeto deseante patológico. La verdad se desplazaba no hacia el deseo, sino a una función biológica y reproductiva. El deseo y el placer se han seccionado de la sexualidad de las mujeres en los dispositivos de enunciación de determinados momentos históricos. Según Butler (1997a: 217), "la asexualidad es algo que a veces está unido en la concepción dominante de la mujer heterosexual". Foucault aborda el desplazamiento de la sexualidad femenina hacia lo patológico en su Historia de la sexualidad pero, no obstante, no atiende a esta construcción paradójica de la asexualidad, que dejaría en silencio el placer femenino.

Es pertinente recordar cómo en obras clásicas de esta producción discursiva incesante, como resulta el caso de Havelock Ellis, se constituye una sexualidad femenina en la que el dolor es el placer 
(Martín González, 2003: 84), llevando a cabo una operación que ha sido reiterada por muchos varones situados en posiciones autorizadas de enunciación discursiva, desde la medicina hasta la filosofía: detentar un saber tiránico que sanciona como placer lo que probablemente el individuo que lo experimenta vive como sufrimiento o dolor. Tal posición privilegiada "interpretativa" no sólo ha sido establecida en los discursos sobre la sexualidad, aunque quizá sea éste el terreno de mayor ocurrencia; también la filosofía ha sido territorio de extraordinaria prolijidad en relación con el interpretante-autorizado-varón acerca de los sentimientos, pensamientos de un sujeto "mujer/es".

En un intento por averiguar las formas en que los individuos son llevados a reconocerse como sujetos sexuales Foucault se plantea, como hemos mencionado, una genealogía del hombre de deseo. Pero ¿quién es ese sujeto que desea? Como señala Rodríguez Magda, hablar del "hombre de deseo" introduce una penosa ambigüedad (Rodríguez Magda, 1999). Aunque Foucault es consciente del carácter viril de las prácticas que estudia, esto no merece ser problematizado en sus propios análisis:

"Es cierto. La ética griega del placer se vincula con la sociedad viril, con la disimetría, con la exclusión del otro, con una obsesión por la penetración y con una especie de amenaza de ser desposeído de la propia energía entre otros temas. ¡Todo esto es bastante desagradable!." (Foucault, 1984e: 614).

El sujeto de deseo "mujer" ha sufrido avatares más complejos en función de un orden androcéntrico: ha sido sujeto pero también, de forma ambivalente y compleja, objeto del deseo de los otros; ha pensado su sexualidad vinculada por un lado a la reproducción sin placer -como señala Laqueur en relación con el "descubrimiento" de que el orgasmo femenino no era necesario para la procreación (Laqueur, 1994) - y por otro a la patología (la histeria, la criminalización). En algunos momentos históricos, como durante la dictadura franquista, las instancias de producción discursiva de la feminidad lo que hacían casi exclusivamente en relación con la sexualidad, era manejar silencios, incitar prohibiciones, fomentar ignorancias sistemáticas. ${ }^{9}$ Todo ello en una maraña densa de retórica religiosa y especialmente culpabilizadora, junto con prácticas disciplinarias de explícita obediencia al varón y estrategias de reproducción del cuerpo social para gloria de la patria/raza y que hemos analizado en otro lugar (Amigot, 2005). Habitualmente en tales contextos, las mujeres no hablaban de sexo. Y hablar, en tales situaciones, puede suponer la conquista de un decir y de un saber que subvierte la identidad normativa y abre la posibilidad del placer y de la creación.

\section{Las prácticas de sí}

Como hemos señalado, hay autoras que consideran que la elaboración de la ética foucaultiana, con la referencia a los procesos de subjetivación que exceden los términos en los que previamente habían sido pensados por Foucault, son logros susceptibles de utilización feminista.

\footnotetext{
${ }^{8}$ Michèle Le Doeuff realiza un prodigioso análisis de parte de la obra de Sartre observando tal fenómeno (Le Doeuff, 1993).

9 "Buscar en cambio las instancias de producción discursiva (que también ciertamente manejan silencios) de producción de poder (cuya función a veces es prohibir) de las producciones de saber (que a veces hacen circular errores o ignorancias sistemáticos)" (Foucault, 1976b: 21).
} 
De todas formas, el hecho de desarrollar su reflexión acerca de los procesos de subjetivación en relación con "las artes de la existencia", plantea algunos problemas. Las reflexiones griegas atendidas por Foucault, cuya base se encuentra en el cuidado del cuerpo y el cuidado de sí posteriormente, y en cuya estilización originarán una ética y una estética, reposan, como hemos señalado, en un modelo viril. Este modelo aborda la relación de dominio de sí de un sujeto que domina a otros, y que como debe dominar a otros debe aprender a dominarse a sí mismo. Es decir, es un proceso complejo de cuidado de sí que se sustenta sobre una estructura de dominio.

En esta estructura son las mujeres, junto a otros colectivos, quienes ocupan las posiciones de dominadas, quienes quizá actúan como elemento dialéctico y regulador de la posición del sujeto libre. De hecho, la relación con los efebos, la práctica sexual fundamentalmente problematizada en la Grecia clásica, se sitúa sobre el eje de la relación asimétrica vinculado a la distinción actividad/pasividad. Aunque en el efebo la posición pasiva no se vincule a una "esencia" o "sustancia" puesto que "efebo" es una posición temporal. Pero esta pasividad era, en el caso de las mujeres, algo consustancial a ellas. Ese cuerpo que se cuida es un cuerpo masculino, al que debía preceder toda una anatomía filosófica que pasa por la diferencia sexual, puesto que "es en su relación con lo que no es él, la naturaleza y el cuerpo femenino, donde el masculino encuentra su identidad y su ideal regulativo" (Rodríguez Magda, 1999: 254).

Rodríguez Magda ha señalado además la elusión de cualquier reflexión sobre lo afectivo-emocional en la genealogía foucaultiana de la sexualidad y de la moral antigua. Quizá, a nuestro entender, esto tenga algo que ver con la falta de la "dimensión psíquica" que Butler señala en la analítica del autor en relación con los procesos de sujeción y los dispositivos de poder (Butler, 1997b). Cuando Foucault habla de "hombre de deseo" se refiere a la objetivación que los discursos y prácticas hegemónicas han establecido en relación con la construcción imaginaria y progresiva de un sujeto racional pero encadenado a un cuerpo cuyo deseo deviene en verdad y pecado oculto. En su análisis parece no problematizar, precisamente, aquello que se ha proyectado históricamente en lo femenino: las emociones; y no las aborda explícitamente en relación con los procesos de subjetivación.

Por último, en el desarrollo teórico de las prácticas de sí y de las prácticas de libertad, Foucault no parece atender de manera particular a los diferentes grados de sujeción que limitarían la posibilidad de una autocreación. Como hemos visto, sí distingue entre estados de dominación y otras situaciones estratégicas de poder, pero no problematiza esta distinción; apuntará, eso sí, que en situaciones de dominación es necesario un proceso de "liberación" para poder desarrollar prácticas de sí que permitan un eventual ejercicio de la libertad (Foucault, 1984f, p. 710).

Tal desatención puede vincularse con lo que Rodríguez Magda (1999: 25) considera una paradoja de la obra foucaultiana: que no aplique al estudio de la subjetivación su analítica del poder. Esto puede ser debido a un análisis histórico específico, el de sujetos privilegiados de la Antigüedad grecolatina, que ha condicionado ampliamente las consideraciones y reflexiones generales de Foucault acerca del sujeto moral y las prácticas de libertad, y a la interrupción de sus análisis con su muerte.

De hecho, en el Uso de los placeres, no acomete el análisis de algo que, por otra parte y según cómo leamos sus palabras, se revela claramente en el texto. Como hemos indicado más arriba, Foucault distingue entre morales basadas en el código y morales basadas en la ética. Estas últimas serían las que sitúa en las sociedades griegas y romanas (aunque reconoció que se trataba de una élite social). Al atender a la actitud y reflexiones sobre el sexo fuera del matrimonio, Foucault considera que era el varón libre quien debía limitar sus opciones sexuales en cuanto tenía autoridad, y que "en la moral 
antigua, el dominio de sí es sólo un problema del individuo que debe ser dueño de sí y dueño de los demás, y no para quien debe obedecer (...) la ética sólo concierne a los hombres" (Foucault, 1984g, 673). La mujer debía, simplemente, obedecer. Vemos, por tanto, cómo dos posiciones de poder distintas implican posibilidades muy diferentes en el cuidado de sí: la actividad de la mujer estaba regulada por la obediencia, que debía ser una de sus virtudes identitarias, vinculada a un código determinado. Es el varón, en tanto autoridad en ese tejido de relaciones, quien problematiza y responde a las demandas reflexionando y ejercitándose en determinadas virtudes. Moral orientada al código para una, orientada a la ética para el otro.

\section{Proliferaciones de una lectura crítica}

Una de las críticas a Foucault desde posiciones feministas ha sido la evanescencia que su conceptualización de poder implicaba para una práctica de denuncia concreta; si el poder no es propiedad de nadie, es problemático imputar su responsabilidad o su abuso a individuos o colectivos. Las instancias de poder, de tan complejas, se desvanecerían. Considerando lo que hemos expuesto, creemos que sería necesario matizar esto y establecer elementos que favorezcan un diálogo teórico.

Por un lado, se intuye en algunas de estas críticas una cierta necesidad implícita de fundamentar las luchas políticas y las consideraciones éticas en términos epistemológicos. Sin embargo, aun desdeñando el postulado de la propiedad (del poder), Foucault reconoce que, como fórmula política, "ellos tienen el poder" es valiosa, aunque sea problemática epistemológicamente porque consiste en una operación de homogeneización teórica. Aunque ello las sitúe en una tensión interminable, las acciones políticas tienen una dimensión pragmática que no debiera ser bloqueada por la necesidad epistemológica de descubrir la verdad, más aún si se parte de una posición que subraya la naturaleza contingente e histórica del conocimiento. A este tipo de dificultades, repetidas en las discusiones feministas, alude Anne Phillips (1992: 28) como "las eternas dificultades que supone deducir la política de posiciones filosóficas". Creemos que la teorización foucaultiana multiplica, no asfixia, las posibilidades de subversión política, en tanto considera las nociones de poder y libertad en su dimensión práctica y situada. Son, pues, el análisis práctico de los efectos y la atención a sus desplazamientos históricos los que pueden regular la propia estrategia de subversión o transformación.

Consideramos, sin embargo, que Foucault no abordó de manera efectiva situaciones particulares de dominación como la que regula la producción y relación entre los sexos. Consideraba la "unidad global de dominación", la ley o la soberanía del Estado, formas terminales del poder (Foucault, 1976a) a las que no atendió prioritariamente dado su carácter secundario de cristalización de situaciones estratégicas más complejas y amplias. Pero al establecer este tipo de distinciones, por ejemplo, entre relaciones de poder y relaciones violentas, o entre relaciones de poder y esclavitud (Foucault, 1982) oscurece la consideración de una gradación intermedia en la que se juega un mayor o menor constreñimiento de lo posible. Si las determinaciones son absolutas no puede hablarse de poder, dice, sino de esclavitud; no obstante, hay situaciones que determinan más que otras y son, precisamente, las que las mujeres han vivido históricamente, por lo menos en los últimos siglos: eran libres, pero menos que otros. Algunas autoras, en relación con esto, consideran que Foucault estableció una dicotomía simplista y falsa entre poder, por un lado, y violencia o dominación, por otro (Deveaux, 1994). Sin compartir del todo tal aseveración, sí parece que Foucault estableció una cierta contraposición dentro de esta distinción conceptual que, desde el análisis feminista, no 
deja de ser problemática; quizá sería más adecuado concebir tal distinción como una progresión o un entrelazamiento más complejo y gradual, puesto que es, precisamente, en ese tránsito o espacio intermedio en el que se ha movido y se mueve la práctica feminista. De todas maneras, creemos que el planteamiento foucaultiano tiene gran virtualidad teórica en cuanto permite, así mismo, no asimilar siempre la desigualdad de género a una situación de dominación y matizar las diferencias en relación con el poder de colectivos diversos de mujeres.

Considerando la pertinencia del paradigma estratégico del poder, de su naturaleza histórica y contingente y de su carácter multiforme, creemos que en el análisis de las relaciones de poder resulta adecuada, en primer lugar, una perspectiva situada y localizada y una exploración, tanto de las relaciones de poder como de las de resistencia, en contextos específicos; adentrarse, más allá de la mera consideración homogeneizadora de constantes históricas, en el análisis de situaciones y prácticas concretas. En segundo, la problematización de la tensión entre poder y libertad con el atravesamiento de la construcción de las diferencias sexuales como dispositivo que complejiza el análisis, tanto de los procesos de subjetivación como de las condiciones de posibilidad de las resistencias y de las prácticas de libertad. Porque en el análisis del dispositivo de género, la corporeización de los efectos del poder adquiere especial visibilidad, se despliega indicando la existencia de complejos procesos y mecanismos psíquicos, en palabras de Butler (1997b), afectivos y no conscientes. $Y$ porque el análisis de las posibilidades de agencia $y$, más allá, de prácticas de libertad, requiere de una especial consideración de los impedimentos, malestares y sufrimientos sin nombre, así como de las estrategias que habitualmente no se adecuan al modelo de las tácticas de lucha.

El análisis situado e histórico es interesante porque los discursos y las disciplinas son complejas y variadas. Pensamos que en determinados momentos se ha dado una sobredeterminación de lo femenino y de las mujeres, pero no por una opresión simple y unificada sino por una reiterada proliferación de discursos y prácticas que las describen y prescriben; incluso en ocasiones, como en la actualidad (pero eso es otra cuestión), de maneras contradictorias y complejas. Foucault despliega un abanico extraordinario sobre el que indagar, considerando simultáneamente tal diversidad de los mecanismos de sometimiento así como la posibilidad de rastrear múltiples resistencias. Esto concuerda con la idea de que los mandatos de género se dan en implicación con otros campos discursivos, coexisten y se reorientan con éstos, como plantea Butler (1990).

Una mirada que simplifique las situaciones de dominación estableciendo un esquema dual entre dominadores y sometidas, además de olvidar los sometimientos que también regulan la vida de "los dominadores", oscurece las estrategias de resistencia que determinados grupos de mujeres han ejercido. Ha habido mujeres, consideradas como inexorablemente sometidas y difícilmente "liberables", mujeres constreñidas ciertamente por unas prácticas extraordinariamente restrictivas, que, no obstante, en contextos específicos, han tejido sus espacios de resistencia e incomodidad dentro de mandatos hegemónicos.

Las técnicas de sí leídas y problematizadas desde una perspectiva de género permiten establecer una conexión entre las técnicas de dominio y las técnicas de sí, porque en las "mallas del poder" que nos atrapan, hombres y mujeres disponen de formas de tomarse a sí mismos como objetos y transformarse que están marcadas por el género. Tal lectura permitiría indagar en las condiciones de posibilidad del ejercicio de prácticas de libertad. Hay dispositivos normalizadores y definiciones que en su práctica incitan a reconocerse y transformarse una/o misma/o mediante procesos, en ocasiones, genéricamente diferentes. El género deviene, tal como ha señalado Butler (1990), un 
locus de significados culturales en cuyo contexto se marca un proceso corpóreo de interpretación. El estudio de los procesos de subjetivación desde la consideración central del cuerpo como espacio de significaciones y afectos, atravesado por procesos semiótico-materiales que lo hacen inteligible y lo constituyen como cuerpo sexuado, es una de las exploraciones que parte de la teoría feminista, atendiendo a esos dispositivos móviles de poder situados que nos generan como sujetos, ha intensificado en su recorrido polémico y fascinante por este laberinto.

En la indagación de este espacio vincular entre técnicas de dominio y prácticas de sí, así como en la tensión entre prácticas de sí y ejercicio de la libertad, nos resulta muy relevante la consideración de la intersubjetividad. Algo ciertamente difuso en el análisis de Foucault.

En primer lugar, creemos que los procesos de constitución de la subjetividad y su producción de efectos encarnados que sedimentan dispositivos hegemónicos pasan, precisamente, por la intersubjetividad. En segundo lugar, tales consideraciones inducen a contemplar asimismo la intersubjetividad como el espacio de posibilidad para la transformación de las relaciones de poder. Una intersubjetividad que problematiza las identidades sexuales configuradas y desplaza los juegos de verdad en los que éstas se inscriben, fractura y permite la resignificación y la modificación de prácticas. Las reglas que regulan los juegos de verdad, como hemos apuntado, nunca son individuales ni trascendentes: se actúan y se reactualizan en las prácticas, discursivas y no discursivas. La práctica intersubjetiva deviene así un lugar de "empoderamiento" y la posibilidad de ejercicio de prácticas de libertad para algunos colectivos de mujeres. Las luchas de las mujeres se han articulado en muchas ocasiones de esta forma. Y las prácticas, como las problematizaciones, abren espacios cuyos efectos son imposibles de determinar desde el principio.

Como apuntamos al comienzo de este trabajo, el análisis del poder y de la libertad, o de la sujeción y de la subversión entraña la consideración de sus mutuas implicaciones. Estos procesos, enmarañados como están en una compleja articulación, es necesario contemplarlos en su imbricación mutua, recíprocamente iluminadora. $\mathrm{Y}$ en este análisis consideramos importante introducir la perspectiva de género como análítica de poder, por lo menos en procesos contextualizados en sociedades como la nuestra en las que el género es un principio de regulación difícilmente soslayable. Como todo dispositivo de poder, las estrategias son móviles, múltiples y cambiantes. Su análisis sólo nos permite pensar qué somos pero no qué estamos ya, siendo, como dice Deleuze, dentro de esta madeja que conforma un diagrama de visibilidad y de enunciación que nos produce y que huye fugazmente.

"El estudio de los procesos de subjetivación parece ser una de esas tareas fundamentales que Foucault dejó a quienes habrían de seguirlo. [...] toda una tipología de formaciones subjetivas en dispositivos móviles". (Deleuze, 1989: 157).

Por todo ello, más que ver una limitación negativa en la obra de Foucault, tal como se apunta desde algunas lecturas feministas que consideran inadecuado el conjunto de instrumentos teóricos foucaultianos, creemos que sus planteamientos entrañan una gran fertilidad. Las contradicciones o rechazos tajantes pueden ser producto de una previa configuración abstracta y dualista, tanto de las opresiones como de los tópicos del poder y de la libertad. Precisarlos en un contexto histórico detallado ayuda a contemplarlos en procesos cambiantes de los que hacer la genealogía y en una relación mutuamente condicionadora. El análisis de los dispositivos de género puede aportar inteligibilidad en tales consideraciones conjuntas de la sujeción y de la libertad. Al respecto, nos resultan sugerentes las propuestas llevadas a cabo en la literatura feminista, en la que la perspectiva 
de género incorpora a la pregunta por la libertad la memoria de las estrategias de poder que constituyen sujetos sexuados, que nos constituyen como sujetos sexuados (Rodríguez Magda, 1999).

El carácter no totalizador ni hermético de las reflexiones de Foucault multiplica las preguntas y bosqueja lagunas y desconciertos, pero también el vértigo que incita a seguir explorando y actuando. Rotos los hilos identitarios, las inquietudes y las dudas se convierten en espléndidos laberintos por los que perderse para re -encontrarse sucesivamente. Seguir pensando y, como señalaba este autor:

"hacerse libre para pensar y amar aquello que, en nuestro universo ruge desde Nietzsche; diferencias insumisas y repeticiones sin origen." (Foucault, 1969a: 798).

\section{Referencias}

Allen, Amy. (2004). Foucault, feminism and the self: The politics of personal transformation. In Dianna Taylor \& Karen Vintges (Eds.). Feminism and the final Foucault (pp. 235-257). Chicago: University of Illinois Press.

Amigot, Patricia. (2005). Relaciones de poder, espacio subjetivo y prácticas de libertad. Análisis genealógico de un proceso de transformación de género. Tesis Doctoral. Universitat Autonoma de Barcelona, Barcelona.

Amorós, Celia. (1994). Feminismo, ilustración y post-modernidad: Notas para un debate. En Celia Amorós (Ed.). Historia de la teoría feminista (pp. 339-352). Madrid: Comunidad de Madrid. Instituto de Investigaciones Feministas.

Amorós, Celia. (1997). Tiempo de feminismo: Sobre feminismo, proyecto ilustrado y postmodernidad. Madrid: Cátedra.

Bartky, Sandra Lee. (1988). Foucault, feminity and the modernization of patriarchal power. In Irene Diamond \& Lee Quinby (Eds.). Feminism and Foucault: Reflections on resistence. (61-85) Boston: Northeastern University Press. Traducción: Foucault, feminismo y la modernización del poder patriarcal. En Elena Larrauri (comp.): Mujeres, derecho penal y criminología (6393). Madrid: Siglo XXI, 1994.

Bartky, Sandra Lee. (1990). Feminity and Domination. Nueva York: Routledge. Existe traducción de dos capítulos: Pedagogía de la vergüenza. En Carmen Luke (1999). Feminismos y pedagogías en la vida cotidiana (211-225). Madrid: Morata.

Beaulieu, Alain. (2004). Gouvernementalité. In Stéfan Leclercq (Ed.), Abécédaire de Michel Foucault (pp. 54-56). Paris: Sils Maria asbl.

Benhabib, Seyla. (1992). Situating the self. Gender, community and postmodernism in contemporary ethics. Cambridge: Polity Press.

Bordo, Susan. (1988). Anorexia nervosa: Psychopathology as the chrystallization of culture. In Irene Diamond \& Lee Quinby (Eds.). Feminism and Foucault (pp. 87-118). Boston: Northeastern University Press. 
Bordo, Susan. (1993). Feminism, Foucault and the politics of the body. In Caroline Ramazanoglu (Ed.). Up against Foucault. Explorations of some tensions between Foucault and feminism. Londres-Nueva York: Routledge.

Braidotti, Rosi. (1991). Patterns of dissonance: A study of women in contemporary philosophy. New York: Routledge.

Braidotti, Rosi. (2004). Feminismo, diferencia sexual y subjetividad nomade. Barcelona: Gedisa.

Butler, Judith. (1990). El género en disputa. El feminismo y la subversión de la identidad. MexicoBuenos Aires-Madrid: Paidós, 2001.

Butler, Judith. (1997a). Lenguaje, poder e identidad. Madrid: Síntesis, 2004.

Butler, Judith. (1998). Fundamentos contingentes: el feminismo y la cuestión del "posmodernismo". Traducción de Piera Oria. Buenos Aires. Centro de Documentación de la Mujer.

Butler, Judith. (1997b). Mecanismos psíquicos del poder: Teorías sobre la sujeción. Madrid: Cátedra, 2001.

Butler, Judith. (2001). Encuentros transformadores. In Elisabeth Beck-Gernsheim, Judith Butler \& Lidia Puigvert (Eds.). Mujeres y transformaciones sociales (pp. 77-91). Barcelona: El Roure.

Butler, Judith. (2004). Changing the subject: Judith Butler's politics of radical resignification. In Sara Salih \& Judith Butler (Eds.). The Judith Butler reader (pp. 325-356). Oxford: Blackwell.

Cabruja i Ubach, Teresa. (2003). Astucias de la razón y psicología crítica: Condiciones de erotismoseducción, prácticas de tokenismo y resistencias ético-políticas. Política y sociedad, 40(1), 141-153.

Canguilhem, Georges. (1989). Presentation. In Etienne Balbier, Gilles Deleuze, Hubert L. Dreyfus et al. (Eds.). Michel Foucault philosophe (pp. 11-12). Paris: Éditions du Seuil.

Caplan, Patricia. (1987). The cultural construction of sexuality. London; New York: Tavistock Publications.

Cruz, Manuel. (2002). Filosofía contemporánea. Madrid: Santillana-Taurus.

De Lauretis, Teresa. (1990) Sujetos excéntricos. En: Tersa De Lauretis. Diferencias. Etapas de un camino a través del feminismo (111-152). Madrid. Horas y horas, 2000.

De Lauretis, Teresa. (2000). Diferencias. Etapas de un camino a través del feminismo. Madrid: Horas y horas.

Deleuze, Gilles. (1989). ¿Qué es un dispositivo?. In Etienne Balbier, Gilles Deleuze, Hubert L. Dreyfus et al. (Eds.). Michel Foucault, filósofo (pp. 155-163). Madrid: Gedisa, 1990.

Deveaux, Monique. (1994). Feminism and empowerment: And critical reading of Foucault. Feminist Studies, 20(2), 223-247.

Dreyfus, Hubert, \& Rabinow, Paul (1984). Michel Foucault: Un parcours philosophique. Paris: Gallimard. 
Ehrenreich, Barbara y English, Deirdre. (1990). Por su propio bien. 150 años de consejos de expertos a las mujeres. Madrid: Taurus.

Foucault, Michel. (1969a). Ariane s'est pendue. In Daniel Defert \& François Ewald (eds). Dits et écrits. Vol.I (pp. 767-771). Paris: Gallimard, 1994.

Foucault, Michel. (1969b). L'archéologie du savoir. Paris: Gallimard.

Foucault, Michel. (1973). Prisons et révoltes dans les prisons. Daniel Defert \& François Ewald (eds). Dits et écrits. Vol.II (pp. 425-432). Paris: Gallimard, 1994.

Foucault, Michel. (1974). La vérité et les formes juridiques. In Daniel Defert \& François Ewald (eds). Dits et écrits. Vol.II (pp. 538-646). Paris: Gallimard, 1994.

Foucault, Michel. (1975). Asiles, sexualité, prisons. In Daniel Defert \& François Ewald (eds). Dits et écrits. Vol.II (pp. 771-802). Paris: Gallimard, 1994.

Foucault, Michel. (1976a). Cours du 14 du janvier 1976. In Daniel Defert \& François Ewald (eds). Dits et écrits. Vol.II (pp. 175-189). Paris: Gallimard, 1994.

Foucault, Michel. (1976b). Histoire de la sexualité, I: La volonté de savoir. Paris: Gallimard.

Foucault, M. (1977a). Le jeu de Michel Foucault. In Daniel Defert \& François Ewald (eds). Dits et écrits. Vol.III (pp. 298-329). Paris: Gallimard, 1994.

Foucault, Michel. (1977b). Pouvoirs et stratégies. In Daniel Defert \& François Ewald (eds). Dits et écrits. Vol.III (pp. 418-428). Paris: Gallimard, 1994.

Foucault, Michel. (1977c). Non au sexe roi. In Daniel Defert \& François Ewald (Eds.). Dits et écrits. Vol. III. (pp. 256-269). Paris: Gallimard, 1994.

Foucault, Michel. (1977d). Entretien avec Michel Foucault. In Daniel Defert \& François Ewald (Eds.). Dits et écrits. Vol. III (pp. 140-160). Paris: Gallimard, 1994.

Foucault, M. (1978). Dialogue sur le pouvoir. In Daniel Defert \& François Ewald (Eds.). Dits et écrits. Vol. III. (pp. 464-477). Paris: Gallimard, 1994.

Foucault, Michel. (1981a). Sexualité et solitude. In Daniel Defert \& François Ewald (Eds.). Dits et écrits. Vol. IV. (pp. 168-178). Paris: Gallimard, 1994

Foucault, Michel. (1981b). Subjectivité et verité. In Daniel Defert \& François Ewald (Eds.). Dits et écrits. Vol. IV. (pp. 213-219). Paris: Gallimard, 1994

Foucault, Michel. (1982). Le sujet et le pouvoir. In Daniel Defert \& François Ewald (Eds.). Dits et écrits. Vol. VI. (pp. 222-243). Paris: Gallimard, 1994

Foucault, Michel. (1984a). Histoire de la sexualité, II: L'usage des plaisirs. Paris: Gallimard.

Foucault, Michel. (1984b). Interview de Michel Foucault. In Daniel Defert \& François Ewald (Eds.). Dits et écrits. Vol. IV (pp. 688-696). Paris: Gallimard, 1994.

Foucault, Michel. (1984c). Le retour de la morale. In Daniel Defert \& François Ewald (Eds.). Dits et écrits. Vol. IV (pp. 696-708). Paris: Gallimard, 1994. 
Foucault, Michel. (1984d). Qu'est-ce que les lumières?. In Daniel Defert \& François Ewald (Eds.). Dits et écrits. Vol. IV (pp. 562-578). Paris: Gallimard, 1994.

Foucault, Michel. (1984e). Á propos de la généalogie de l'éthique: Un aperçu du travail en cours. In Daniel Defert \& François Ewald (Eds.). Dits et écrits. Vol. IV (pp. 609-631). Paris: Gallimard, 1994.

Foucault, Michel. (1984f). L'éthique du souci de soi comme pratique de la liberté. In Daniel Defert \& François Ewald (Eds.). Dits et écrits. Vol. IV (pp. 708-729). Paris: Gallimard, 1994.

Foucault, Michel. (1984g). Le souci de la verité. In Daniel Defert \& François Ewald (Eds.). Dits et écrits. Vol. IV (pp. 668-679). Paris: Gallimard, 1994.

Foucault, Michel. (1988). Les techniques de soi. In Daniel Defert \& François Ewald (Eds.). Dits et écrits. Vol. IV (pp. 783-813). Paris: Gallimard, 1994.

Fraser, Nancy, \& Hanneth, A. (1998). Redistribution or recognition? A political-philosophical exchange. London: Verso.

Fraser, Nancy. (1989). Unruly practices. Power, discourse and gender in contemporary social theory. Minneapolis: University of Minnesota Press.

Fuss, Diane. (1989). Essentially speaking: Feminism, nature and difference. London: Routledge.

García Dauder, Silvia y Romero Bachiller, Carmen. (2004). Vigilando las fronteras del sexo: La construcción médica del "sexo verdadero". En Agustín Vicente (Ed.). Actas del IV congreso de la sociedad de lógica, metodología y filosofía de la ciencia de España (pp. 446-450). Valladolid: Mata Digital, S.L.

Gómez, Lucía. (2004). Subjetivación y feminismo: Análisis de un manifiesto político. Atenea Digital(5), 97-123. Accesible en http://antalya.uab.es/athenea/num124/gomez.pdf

Hekman, Susan J. (2004). Feminist identity politics: Transforming the political. In Dianna Taylor \& Karen Vintges (Eds.). Feminism and the final Foucault (pp. 197-213). Chicago: University of Illinois Press.

Ibáñez, Tomas. (2001). Municiones para disidentes. Realidad-verdad-política. Barcelona: Gedisa.

Kaplan, Caren. (1987). Deterritorializations: The rewriting of home and exile in western feminist discourse. Cultural Critique, 6, 187-198.

Laqueur, Thomas. (1994). La construcción del sexo: Cuerpo y género desde los griegos hasta Freud. Madrid: Cátedra.

Larrauri, Maite. (1996). La espiral foucaultiana. Del pragmatismo de Foucault al pensamiento de la diferencia sexual. Valencia: Episteme.

Larrauri, Maite. (1999). Anarqueología. Teoría de la verdad en Michel Foucault. Valencia: Eutopías.

Le Blanc, Jocelyne. (2004). L'arquéologie du savoir de Michel Foucault pour penser le corps sexué autrement. Paris: L'Harmattan. 
Le Doeuff, Michèle. (1993). El estudio y la rueca. De las mujeres, de la filosofía, etc. Valencia: Cátedra.

López Alvarez, Pablo y Muñoz, Jacobo. (2000). La impaciencia de la libertad. Michel Foucault y lo político. Madrid: Biblioteca Nueva.

López Pardina, Teresa. (2003). Feminismo y filosofía. Aplicaciones feministas de la filosofía foucaultiana. En Teresa López Pardina y Asunción Oliva (Eds.). Crítica feminista al psicoanálisis y a la filosofía (pp. 209-234). Madrid: Instituto de Investigaciones Feministas. Universidad Complutense de Madrid.

Martín González, Matilde. (2003). Discursividad sexual y poder disciplinario: Una visión foucaultiana en la obra de tres poetas norteamericanas. Santa Cruz de Tenerife: Universidad de La Laguna.

McLaren, Margaret A. (2004). Foucault and feminism: Power, resistance, freedom. In Dianna Taylor \& Karen Vintges (Eds.). Feminism and the final Foucault (pp. 214-234). Chicago: University of Illinois Press.

McNay, Lois. (1992). Foucault and feminism: Power, gender and the self (1st ed.). Cambridge: Polity Press.

McNay, Lois. (2000). Gender and agency: Reconfiguring the subject in feminist and social theory. Malden, Mass.: Polity Press.

Moi, Toril. (1985). Power, sex and subjectivity: Feminist reflections on Foucault. Paragraph: Journal of the Modern Critical Theory Group(5), 95-102.

Nicholson, Linda. (Ed.). (1990). Feminism/postmodernism. London: Routledge.

Nussbaum, Martha C. (1999). Sex and social justice. Oxford: Oxford University Press.

Pardo, José Luis. (2000). Máquinas y componendas. La filosofía política de Deleuze y Foucault. En Pablo López Álvarez y Jacobo Muñoz (Eds.), La impaciencia de la libertad. Michel Foucault y lo político (pp. 23-84). Madrid: Biblioteca Nueva.

Perrot, Michèlle. (1997). De Mme. Jourdain à Herculine Barbin: Michel Foucault et l'histoire des femmes. In Dominique Franche, Sabine Prokhoris \& Yves Roussel (Eds.). Au risque de Michel Foucault (pp. 95-108). Paris: Éditions du Centre Pompidou.

Phillips, Anne. (1992). Las pretensiones universales del pensamiento político. En Michelle Barrett y Anne Phillips (Comp.) Desestabilizar la teoría. Debates feministas contemporáneos. México: Paidós, 2002.

Pujal i Llombart, Margot. (2003). La tarea crítica: Interconexiones entre lenguaje, deseo y subjetividad. Política y sociedad, 40(1), 129-140.

Rodríguez Magda, Rosa María. (1999). Foucault y la genealogía de los sexos. Barcelona: Anthropos.

Romero Pérez, Rosalía. (1996). En torno al pensamiento crítico: Michel Foucault y la teoría feminista. Universidad Complutense de Madrid, Madrid.

Sawicki, Jana. (1991). Disciplining Foucault. Feminism, power and the body. New York: Routledge. 


\section{Historia editorial}

Recibido: 05/10/2005

Aceptado: 22/03/2006

\section{Formato de citación}

Amigot, Patricia y Pujal, Margot. (2006). Ariadna danza: lecturas feministas de Michel Foucault. Athenea Digital, 9, 100-130. Disponible en http://antalya.uab.es/athenea/num9/amigot.pdf

Patricia Amigot Leache. Doctora en Psicología Social por la UAB y Profesora ayudante en el Dpto. de Trabajo Social de la Universidad Pública de Navarra. Imparte docencia en Psicología Social, e Intervención Social con Grupos. Líneas de investigación y publicaciones en: Teoría feminista y de Género, Relaciones de poder y Procesos de subjetivación. Miembro del Grupo de Investigación "Dessujectant: Estudis socials de la Subjecció i Subjectivitat"

Margot Pujal i Llombart. Profesora Titular y Doctora de Psicología Social. Departamento de Psicología Social de la Universidad Autònoma de Barcelona. Imparte docencia en Psicologia Social, Psicologia de la Acción Colectiva y Teoría de las Relaciones de Género. Líneas de investigación y publicaciones en: Relaciones de poder, Sujeción y Subjetividad, Ciencia y Género, Feminismo y Psicología. Coordinadora grupo de investigación "Des-subjectant: Estudis socials de la Subjecció i Subjectivitat".

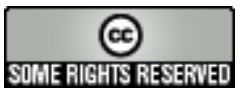

Este texto está protegido por una licencia Creative Commons.

Usted es libre de copiar, distribuir y comunicar públicamente la obra bajo las siguientes condiciones:

Reconocimiento: Debe reconocer y citar al autor original.

No comercial. No puede utilizar esta obra para fines comerciales.

Sin obras derivadas. No se puede alterar, transformar, o generar una obra derivada a partir de esta obra.

\section{$\underline{\text { Resumen de licencia }}$}

$\underline{\text { Texto completo de la licencia }}$ 